Est Ag 44 (2009) 235-275

\title{
La Filosofía como terapéutica vital humana $\left(\mathbf{I}^{\circ}\right)$
}

Sumario: Los pensadores antiguos han dedicado gran parte de su obra a la construcción del hombre o su reforma. En algunos hay como una especie de "ejercicios espirituales", para alcanzar esta meta, como ha estudiado muy bien Pierre Hadot. Varios autores hacen aportaciones decisivas, en ese sentido, desde el punto de vista de la vida filosófica y de la ética, pues, como dice Simplicio, el puesto del filósofo en la ciudad será "el de un escultor de hombres". Y, Cicerón presenta, en Tusculanas III 31, la filosofía como "medicina del alma".

\section{Ejercicios Espirituales en el mundo Antiguo}

El filósofo estructuralista M. Foucault le había aconsejado a Pierre Hadot que presentase su candidatura al Colegio de Francia, pues le confiesa que ha sido un lector muy atento de sus trabajos, especialmente de sus "Exercices spirituels", de l'Annuaire de la Ve Section de l'Ecole Pratique de Hautes Études pour l'année 1975-1976, y que le habían ayudado mucho a escribir la Historia de la Sexualidad, especialmente en el volumen dedicado al cuidado de sí mismo o "le souci de soi". Hablan de los textos de Marco Aurelio y de Séneca, y Foucault le pregunta a Hadot por el significado del vindica tibi (reivindícate a ti mismo) de una carta de Séneca a Lucilio². Luego, Hadot es recibido en el Colegio de Francia, en el que sustituyó al famoso agustinólogo Pierre Courcelle.

\footnotetext{
1 FoucAult, Michel, Histoire de la sexualité, 3. Le souci de soi, Gallimard, Paris 1984.

2 HADOT, Pierre, Un dialogue interrumpu avec Michel Foucault. Convergences et divergences, en Hadot, Pierre, Exercices Spirituels et Philosophie Antique. $3^{\mathrm{a}}$. Institut d'Études Augustiniennes. Paris 1993, 229-333.
} 
Hadot confiesa que: "Bajo la influencia de Bergson, y después del existencialismo, yo he comprendido siempre la filosofía como una metamorfosis permanente de la forma de ver el mundo y de vivir en él"3. Para Epicuro y los Estoicos, la filosofía no es mas terapéutica: "Nuestra única ocupación debe ser la curación": Carta a Meneceo, 122.

Además, según Epicuro, los que se entregan a los placeres "se ven privados del único verdadero placer que es el placer de vivir": EE 25. El placer epicúreo es el placer del pasado y el presente, de contemplar la naturaleza, y el placer de la amistad, que en la comunidad epicúrea supone el examen de conciencia, la corrección fraterna, la confesión pública de las faltas, en un ambiente gozoso y distendido de expansión del corazón, y la felicidad del afecto mutuo y la confianza: EE 28-29.

Es cierto, que un pensamiento puro y universal predispone a la grandeza de alma. La relación más estrecha entre la grandeza de alma y el conocimiento de la Naturaleza se halla en Séneca: "La virtud a la que aspiramos produce la grandeza, porque ella libera el alma, la prepara para el conocimiento de las cosas celestes y la hace digna de participar de la condición divina" (Nat. Quaest. I; CL117,19): La physique comme exercice spirituel chez Marc Aurèle: EE 130.

Toda la actividad moral y filosófica se concentra en el presente: "He aquí todo lo que hace falta: el juicio fiel a la realidad que tú emites en el instante presente, la acción comunitaria que tú realizas en el instante presente, la disposición a acoger con benevolencia en el instante presente todo acontecimiento producido por la causa exterior" (IX,6): La physique comme exercice spirituel: EE 131.

El yo liberado no es egoísta ni pasional sino una persona moral abierta: EE 49. El amor a la sabiduría lleva a la perfección divina. Según la Carta a Meneceo: "Tú vivirás como un dios en medio de los hombres". Lucrecio dice de Epicuro: "Deus ille fuit": EE 50, nota 157. Para Hadot: "La verdadera filosofía es, pues, en la antigüedad, ejercicio espiritual", una auténtica terapéutica, una manera nueva de ver y vivir en el mundo y un esfuerzo de transformación del hombre. Y, así lo ve Aristóteles en la Etica a Nicómaco 1178a.

3 Hadot, Pierre, Exercices Spirituels et Philosophie Antique. $3^{\mathrm{a}}$. Institut d'Études $\mathrm{Au}-$ gustiniennes. Paris 1993,9. En adelante EE. Pronto publica HADOT, P., "Platon et Plotin dans trois sermons de saint Ambroise", en Revue des Etudes Latines, 35(1956), y trabaja sobre la mística de Plotino, Proclo y Damascio, por lo que le fascina el famoso dicho de Wittgenstein: "el mundo es lo místico": Cf.: HADOT, Pierre, Wittgenstein y los límites del Lenguaje, Pre-textos, Valencia 2007, 15-29. 
Según Hadot: El cristianismo, también, se presenta como una filosofía, y esto ocurre especialmente en Clemente de Alejandría, Orígenes, S. Agustín y en el monacato: EE 56. Es la educación del género humano por el Logos, Cristo. Así: "Los discípulos de Bernardo de Claraval eran iniciados en 'las disciplinas de los filosofía celestial'". Se trata de encontrarse a sí mismo y poner atención a Dios (Exercices Spirituels Antiques et Philosophie chretienne: EE 61,62,66), de transformar la propia voluntad y unirla a la Voluntad divina. Y, de este modo, comprendemos el Mundo, la Naturaleza común a los hombres, y la Razón universal": EE 70-714.

El cuidado de sí mismo hace al hombre enfrentarse a su vida. Así, en Sócrates: "Su filosofía es toda ella ejercicio espiritual, nuevo modo de vida, reflexión activa, conciencia viviente": La figure de Socrate: EE 94. En él: "Eros es un daimon, nos dice Diótima, es decir, un intermediario entre los dioses y los hombres": La figure de Socrate: EE 102. Sócrates no es bello ni sabio: "Por eso es philo-sophe, amante de la sabiduría, es decir deseoso de conseguir un nivel de ser que sería el de la perfección divina": La figure de Socrate: EE 103. El sabio, enciende la chispa de Dios y el amor del Logos y "con el amor, el hombre mortal da lo mejor de sí mismo" dice Hölderlin: La figure de Socrate: EE 105.

Para M. Aurelio, que recoge a Epicteto y otros pensadores, el hombre debe establecer:

1.- Una relación apropiada con el mundo (Física).

2.- Una relación adecuada con la causa divina para comprender todas las cosas (Lógica).

3.- Una relación de benevolencia con los otros hombres (Ética).

Se pueden ver estos tres aspectos en sus Pensamientos VIII,27: "Trois rapports:

(1) le premier, avec l'enveloppe que nous entoure,

(2) le second, avec la cause divine, à partir de laquelle tous les événements concourent pour tous les êtres,

(3) le troisiême, avec ceux qui vivent avec nous": Une clé des Pensées de Marc Aurèle: Les trois topoi philosophiques selon Epictète: EE 136.

La primera experiencia se hace en la Física, la segunda en la Lógica y la tercera en la Ética. El hombre es hijo del Logos que construye el hombre interior por la razón, hace la hermandad de los hombres, hijos del Logos,

\footnotetext{
4 ANTOLÍn SÁNCHEZ, Javier, El Epicureísmo en el cristianismo primitivo. Universidad de Valladolid 2003, $328 \mathrm{pp}$.
} 
por la común humanidad, y es el Logos del mundo por las leyes de la Naturaleza: Une clé des Pensées de Marc Aurèle, EE 139.

Se trata de unos ejercicios espirituales que renuevan al hombre, con gozo, por la Física que transforma su mirada sobre el mundo, por la Ética que realiza la justicia en la acción, y por la Lógica que construye nuestros juicios y sentimientos: Une clé: EE 140.

Pero todo está unido, según la tradición estoica: todo es Física, todo es Lógica y todo es Ética. Además, en M. Aurelio, todo tiene una fuerte tonalidad afectiva: "hay que amar a los otros hombres de todo corazón" (VII, $13,3)$, incluso a los malos. Se trata de una recta intención al servicio de la comunidad, un discurso inequívoco, un disposición amorosa ante las cosas de la vida (IV,33): Une clé: EE 147.

$\mathrm{Y}$, si no fuera así, el hombre sería el único ser de la creación que se niega a cumplir su tarea: V,1,3;VII,9. Entonces, la filosofía no trata "tanto de informar al lector de un contenido doctrinal sino de formarle, haciéndole recorrer un itinerario en el curso del cual progresa espiritualmente. Este proceso es evidente en Plotino y Agustín": L'histoire de la pensée hellénistique et romaine. Lección inaugural del Colegio de Francia 18.2. 1983: EE 211.

Es más, el mismo Husserl, en sus Meditaciones Cartesianas, se remite al "hombre interior" de Agustín, y se define como heredero de la tradición del "Conócete a ti mismo" que va de Sócrates a Agustín y Descartes: L'histoire de la pensée hellénistique et romaine: EE 212. A muchos, este proceso les parecerá una fuga mundi. En cambio, incluso M. Foucault ve que, en palabras de Georges Friedmann: "Este esfuerzo sobre sí mismo es necesario, esta ambición, es justa. Son muchos los que se dejan absorber totalmente por la política militante en la preparación de la revolución social. Raros, muy raros, los que al preparar la revolución, quieren hacerse dignos de ella": L'histoire de la pensée hellénistique et romaine: EE $216^{5}$.

Filón de Alejandría nos asegura que los griegos y bárbaros dedicados a la sabiduría, se abstienen de la injusticia, contemplan la naturaleza, se hacen ciudadanos del mundo y su vida es una fiesta, por la alegría de la virtud como su único bien. Esa es su forma de vida: La philosophie comme manière de vivre: EE 218-9.

"Por eso, según Hadot, en lugar de hablar de 'cuidado de sí mismo' (souci de soi), sería mejor hablar de transformación, de transfiguración, de superación de sí mismo": Un dialogue interrumpu "avec Michel Foucault. Convergences et divergences: EE 231.

\footnotetext{
5 FriedmanN, Georges, La Puissance et la Sagesse. Paris 1970, 359.
} 
"El filósofo, al descubrir con Epicuro la inmensidad infinita del universo, experimenta, nos dice Lucrecio, un 'terror sagrado' y una 'seducción divi$n a$ ', que es sin duda, la propia de participar, aunque no sea sino instante, en la maravilla de la vida": Postface à la seconde édition, EE 239. S. Agustín nos dirá en sus Confesiones que ante Dios: inhorresco et inardesco: me horrorizo y me enardezco...

No hace falta ser ningún lince para ver que la interioridad, la comunidad y la acción en s. Agustín, y antes en el cristianismo, resumen, perfectamente, esas tres dimensiones tan fundamentales en los Pensadores Clá$\operatorname{sicos}^{6}$.

\section{El caso de Marco Aurelio y la Ciudadela Interior}

M. Aurelio, en el c. VII ${ }^{\circ}$ de sus Pensamientos o Meditaciones, "ha expresado su reconocimiento a Rústico por haberle apartado de su ambición sofística, de las disertaciones librescas, de las declamaciones pretenciosas, y por haberle revelado que la filosofía es una vida"7. Pero, a veces, hay quién se hace pasar por filósofo para recabar prebendas del emperador: CI 33.

Algunos autores dicen que sus Pensamientos son un "camino hacia sí mismo": CI 39, en un diálogo interior cuyo ejemplo definitivo son los Soliloquios de Agustín (CI 47), pero en M. Aurelio es la "razón que exhorta al alma" y en Agustín es el alma la que escucha a la Razón: CI 47.

Los Pensamientos son como unos ejercicios espirituales que invitan al hombre a vivir la filosofía y mirar al dios interior (II,17,3), no para convertirse en César sino para mantenerse como un hombre más, bueno y justo, conforme a la filosofía (VI,30,1-3), a recogerse en sí mismo (IV,3,1) (CI 5154), a vivir conforme a la Naturaleza, a la comunidad, a Dios, a la vida como don de Dios, mirando al presente con esos temas fundamentales. La razón universal hace unos hombres para otros(CI 56), ciudadanos de un mundo que es como una gran Ciudad (IV,3,5) (CI 58), pues hay un solo mundo, un solo Dios, una sola sustancia, una sola ley, una sola verdad que es su razón común (VII,9): CI 59.

\footnotetext{
6 NATAL, Domingo, "II. Terapéutica. El cuidado de sí mismo (le souci de soi) y la transformación del mundo": Dar alas a la esperanza. Recuperar la persona humana y renovar la confianza social, en Soledad, Diálogo, Comunidad, III Jornadas Agustinianas, Cetesa, Madrid 2000, 128-152.

7 HADOT, P., La citadelle intérieure. Introduction aux Pensées de Marc Auréle. Fayard, Paris 1992, 30. En adelante CI.
} 
Hay tres reglas de vida o disciplinas: de la interioridad, del deseo, y de la realidad, para vivir el propio destino y no ser una marioneta (VII,29) (CI 61,62 ), en la marcha de la vida, como solía ocurrir en tiempo de Vespasiano que, como también dice el evangelio cristiano, se casaban, bailaban, trabajaban, negociaban, etc. (IV,32): CI 63. Pues, hay un ser hegemónico que gobierna la vida, el pensamiento y la libertad (CI 65), y conviene tenerlo cerca. Para eso, M. Aurelio escribe los Pensamientos (III,24,103): CI 65. Ahora bien, "la vida filosófica estoica consiste esencialmente en el dominio (maîtrise) del discurso interior" (CI 65), y eso mismo intenta hacer Epicteto con "el discurso interior de sus oyentes": CI 66.

"Así pues, Marco Aurelio, al escribir sus Pensamientos, practica los ejercicios espirituales estoicos, es decir que él utiliza una técnica, un procedimiento, la escritura, para influirse a sí mismo, para transformar su discurso interior por la meditación de los dogmas y las reglas de vida del estoicismo. Un ejercicio de escritura diario, siempre renovado, siempre retomado, siempre reemprendido, porque el verdadero filósofo es aquel que tiene conciencia de no haber alcanzado aún la sabiduría": CI 67.

Es común a todas las escuelas filosóficas el no dejarse envolver por la palabrería del que no practica "la ciencia de la Naturaleza". Estoicos y epicúreos tenían en común su concentración en el tiempo presente: CI 74. M. Aurelio ha leído a los filósofos desde el punto de vista de Epicteto, y el conocimiento de sus enseñanzas es lo que explica sus Pensamientos, pues, él sigue e imita a Epicteto: CI 74,84.

Se trata de atenerse al principio director, hégemonikon, en la representación, en el impulso a la acción y en el deseo (IX,7): CI 85. El principio de todo estoicismo es "la indiferencia a las cosas indiferentes" y el impulso hacia "el bien moral" como único valor, la intención de hacer el bien que es lo único que depende de nuestra libertad: CI 86. El Mundo, la Razón y la Ley son nuestros guías: CI 91. El sabio estoico es el socio de Dios que es la Razón universal que dirige el hombre y el mundo: CI 92. Y esa divinidad es el Logos que los habita y es Dios: CI 95,98.

El estoicismo de Epicteto dice: Depende de nosotros el juicio de valor, el impulso a la acción y el deseo o aversión (EPIII, 2,1-2): CI 103. La disciplina del deseo no es posible si el filósofo no se considera parte del Todo cósmico. La disciplina del impulso supone la toma de conciencia por la que el filósofo descubre su lugar en la comunidad humana, la disciplina del asentimiento supone la libertad respecto a las representaciones y la leyes de la razón: CI 115.

Arriano utiliza este esquema e investiga las huellas del mismo en Séneca y Cicerón. Es la Física, la Ética y la Lógica como filosofía de la Razón. 
Así: "El filósofo es ciudadano del mundo (I,9,1;II,10,3), pero también ciudadano de la Ciudad humana $(I I, 5,26)$ pequeña imagen de la Ciudad cósmica": CI 116.

\section{1.- El estoicismo de los Pensamientos: La ciudadela interior y la disci- plina del asentimiento}

El conocimiento es sensación que por medio de la fantasía o imagen produce el objeto en la "partie directrice (hégemonikon) de l'àme": CI 119. Para M. Aurelio: "Las cosas, no tocan el alma" (CI 123), ni pueden penetrar en la ciudadela interior. Como dice Epicteto: "Lo que atribula al hombre, no son las cosas, sino sus juicios sobre las cosas" (Manuel 5): CI 125. La paz del alma nace de distinguir, por la razón hegemónica, lo que somos de lo que creemos ser, decir la verdad, aceptar lo que ocurre y hacer lo que es justo (XII,3, 1): CI 130.

La razón hegemónica se nos da "como una fuente de iniciativa, como un 'yo' que decide" y al que debemos escuchar: CI 132. La parte soberana del alma debe permanecer inalterable ante los movimientos del cuerpo (V,26,1; CI 134), pues las cosas pasan mientras la sustancia universal es "como un río en flujo perpetuo" (V,23): CI 135.

M. Aurelio admite un diamon interior igual a la razón directora que Dios ha dado al hombre; seguirlo es dar culto a Dios: CI 140. Su voz se nos impone, dice Epicteto. Y, es: “Alguien que está en mí, más yo que yo mismo", dice P. Claudel con S. Agustín: CI 141. El estoicismo supone un cambio total en la conciencia de sí mismo y del mundo, concentrarse en el presente, una ascética del desprendimiento y reconocimiento del destino de las cosas: CI 137.Y, así, saca sus consecuencias éticas: "He aquí porqué la inteligencia libre de pasiones es una ciudadela. Porque el hombre no tiene ninguna fortaleza que sea más fuerte que esta. Si él se refugia en ella será totalmente inexpugnable" (VIII,48): CI 140.

\section{2. - La disciplina del deseo o el amor fati}

"Nada tiene importancia sino vivir como tu propia naturaleza te manda, y padecer como la Naturaleza común te prescribe"(X,32,2): CI 146. Lo mismo ocurre al actuar y conocer. Así no hay mal posible. La ley fundamental del estoicismo es: "la coherencia consigo mismo, que es al mismo tiempo la ley generatriz de la realidad que rige el pensamiento y la conducta humana": CI 148. El que actúa contra esta razón de la naturaleza común es un miembro separado de la ciudad: CI 148. Por la disciplina del deseo 
debemos desear lo que es útil a todo el mundo, conforme a la razón universal, y por la disciplina del impulso debemos querer lo que sirve a toda la ciudad humana según la recta razón: CI 148. Así: "tomar conciencia del presente es tomar conciencia de nuestra libertad": CI 149.

La felicidad que buscamos consiste en "ordenar el presente conforme a la piedad y la justicia". "Tu verdadera alegría, tu verdadero descanso es: ir de una acción cumplida al servicio de la comunidad a otra acción cumplida al servicio de la comunidad, acompañada del recuerdo de Dios" (VI,7): CI 152.

El verdadero hombre de bien ama y acepta los acontecimientos que vienen a su encuentro siguiendo su propio destino: III,16,3. Como dice Epicteto, y recoge Arriano: “ ¿Vas tú a irritarte, y estar descontento de lo que Dios ha ordenado, esos acontecimientos que él mismo ha determinado y dispuesto, asistido por las Moiras que estaban presentes en tu nacimiento y enfilaron tu destino?" (I,12,25): CI 157. "Entonces, la disciplina del deseo consistirá en colocar cada acontecimiento en la perspectiva del Todo": CI 159. Como la aseguraba Nietzsche: cuando decimos sí a una cosa, lo decimos a la vida y al mundo entero: CI 161. El logos une todas las cosas: la voluntad, la libertad, la razón, y el universo. Como decía Séneca, a cada momento podemos decir con Dios: "Todo es mío": CI 163. Hay que aceptar la parte del todo que nos ha tocado en suerte y el orden en la diversidad de las cosas, pues "si Dios gobierna todo, va bien". Y, como decía Wittgenstein, si entendemos por eternidad "no una duración temporal infinita sino la intemporalidad, entonces aquel que vive el presente vive eternamente": CI $164^{8}$.

"Hay que representarse el impulso original como el efecto de una fuerza que, desde el interior, pone en marcha el proceso de despliegue y expansión del universo": CI 173. El mundo tiene su ley interna que procede de Dios o Logos al que podemos llamar Destino, Providencia, Naturaleza y Mundo (Séneca, Cuestiones Naturales II,46): CI 175. El daimon se identifica, en M. Aurelio, "con la razón interior del hombre, con la naturaleza propia del hombre, que es una parte de la Naturaleza y de la Razón universal (V,27)": CI 177.

Así: "La familiaridad con la Naturaleza, es una de las actitudes fundamentales de quien practica la disciplina del deseo": CI 187. Esta es la Física que abraza la totalidad del cosmos, el infinito y la eternidad "considerando la rápida metamorfosis de todas las cosas". Así: "El alma recorre el mundo entero y el vacío que le rodea, y su forma, y se extiende en el infinito del tiempo finito y abraza y concibe el renacimiento periódico del mundo"

\footnotetext{
8 HADOT, Pierre, Wittgenstein y los límites del Lenguaje, 2007, 50. Hadot fue uno de los primeros en escribir sobre Wittgenstein en Francia.
} 
(XI,1,3): CI 189. Según Séneca, el hombre ha sido hecho para el infinito, y su verdadera patria, su auténtica ciudad es la inmensidad del mundo (CL 102,219): CI 189. Pero, todo lo inspira el amor, y cada parte del mundo es todo el mundo. Así: "La conciencia del yo deviene conciencia del mundo, conciencia de la Razón divina que dirige el mundo": CI 197.

\section{3.- La disciplina de la acción o cómo servir al hombre en la nueva ciu- dad de Dios.}

La disciplina del deseo conduce a la paz del alma, por la aceptación del mundo: CI199. Así, lo propio del hombre es: "Actuar como tu propia naturaleza te manda, sufrir como la Naturaleza común te prescribe" (XII,32,3): CI 200.Todo tiene un fin: "servir a la comunidad humana", sin permitir que el principio hegemónico sea arrastrado como una marioneta por los impulsos egoístas. Por tanto, el sabio debe: "Hacer con toda su alma lo que es justo" (XII, 29,2): CI 202. "Qué más puedo querer si yo actúo en este momento como un ser vivo inteligente, que se pone al servicio de la comunidad humana y se somete a la misma ley de Dios" (VIII,2): CI 204.

El carpintero hace su obra y así muestra lo que es: "Haz tú lo mismo, tu también: come como un hombre, bebe como un hombre, haz tu limpieza, cásate, ten hijos, vive como ciudadano, resiste a los injustos, soporta al hermano, al padre, al hijo, al vecino, al compañero de ruta poco racional. Muéstranos esto, a fin de que veamos si tú has aprendido realmente algo de los filósofos"(III,21,4-6): CI 206. Como la naturaleza ha unido a todos los hombres, éstos deben buscar siempre la utilidad común.

"El único valor absoluto es la intención moral": CI 211. Pues: "La intención buena de Dios vuelve en bien todas las cosas, incluso los obstáculos y las resistencias": CI 215. No hay que buscar recompensa. Como la viña da fruto y la abeja da miel: "Cuando yo he hecho algo al servicio de la comunidad humana, entonces me he sido útil a mí mismo" (XI,4): CI 216. Según Plotino, cuando se es valeroso no hace falta ponderar el propio valor. Lo importante es el servicio a la comunidad: "La Inteligencia de Todo es cuidadosa del bien común de Todos (koinônikos) (V,30)": CI 226. Y es como un buen rey que cuida la ciudad. "La Ciudad más augusta es la Ciudad de lo alto, de la que el hombre es ciudadano y 'de la que las otras ciudades no son más que mansiones"': III, 11,2.

“QQué es el hombre, había dicho Epicteto" (II,5,26): "Una parte de una ciudad, de aquella primera, que está formada por los dioses y los hombres, y después de aquella otra que se denomina así por parecérsele lo más posible y que es una pequeña imagen de la Ciudad universal": CI 227. Para M. 
Aurelio su Ciudad es Roma, como buen Antonino, en cuanto hombre lo es el Mundo, y el bien es lo que es útil a las dos Ciudades (VI,44,6): CI 227. "Es de la Ciudad del Mundo, de la Ciudad de lo alto, que es la Ciudad de los seres racionales, de donde recibimos, dice Marco Aurelio (IV,4,2), la inteligencia, la razón y la ley": CI 227.

Hay que pasar del punto de vista del individuo a la perspectiva universal del todo por medio del logikon (lo razonable) y el koinônikon (cuidadoso del bien común): "Cada ser debe actuar conforme a su constitución. Por su constitución, los otros seres han sido hechos para los seres racionales... y los seres racionales han sido hechos los unos para los otros. Lo que ocupa el primer lugar en la constitución del hombre, es, pues, la tendencia a trabajar por el bien común" (VII,55): CI 228.

El estoicismo parece una doctrina del amor propio y la coherencia propia pero su tonalidad fundamental es el amor del todo pues la coherencia sólo es posible por la adhesión al Todo. Y: "Si el entendimiento divino es cuidadoso del bien común del Todo, es porque él se despliega en este todo. Él es a la vez él mismo y todas las cosas, gracias a una identidad dinámica" (CI 228), pues una es la fuerza que anima todas las cosas. Y: "Es propio del alma racional, amar a su prójimo...y no estimar nada más que a sí misma, lo que es también propio de la ley" (IX,1,4): CI 229. Toda acción que no sirve al bien común es sediciosa y rompe el pueblo, pues ningún miembro vive arrancado del cuerpo; tampoco el que se arranca del Todo por el egoísmo: CI 230. "Aquí se invocan dos disciplinas, la del deseo: aceptar todo lo que acaece, y la de la acción: trabajar por el bien común": CI 230.

Los estoicos reconocen tres niveles de valor: El primero, "vivir de acuerdo con la naturaleza", que se identifica con la virtud, el segundo es el de las cosas indiferentes pero que pueden ayudar a la virtud: salud y riquezas. Y, el tercero, las que en ciertas circunstancias, pueden ser útiles para la virtud aunque en sí no tengan ningún valor.

Para Séneca, la disciplina de la acción funciona de esta manera: primero juzgar del valor en cuestión, luego dar el impulso activo hacia este valor, y finalmente actuar de acuerdo con ese impulso para mantener la coherencia consigo mismo: CI 232. Pero, a la buena disposición debe añadirse la acción. Además: "Los mismos dioses quieren el bien de los hombres. Hasta tal punto son buenos que a menudo ellos mismos les ayudan a obtener la salud, la riqueza, la gloria" (IX,11,2): CI 233. Pero, la única riqueza es la del alma. La justicia estoica consiste en dar a cada cual lo suyo, sin privilegiar nada, y esto no es insensibilidad sino "el amor más puro", según L. Lavelle: CI 238.

La gran tradición socrática, que atraviesa el platonismo y el estoicismo hasta el neo-platonismo, está unida por "la fe en la eminente dignidad de la 
naturaleza humana que se funda en el deseo natural e inconsciente que todo hombre tiene del bien": CI 239. M. Aurelio, siguiendo a Epicteto, tiene un gran respeto por el deseo inconsciente de verdad y de bien "que es el impulso más profundo de la naturaleza racional humana". "Toda alma dice Platón, está privada de la verdad contra su voluntad. Y eso mismo ha de decirse, también, de la justicia, de la templanza, de la benevolencia, y de todas las virtudes análogas. Esto es necesario recordarlo continuamente. Así tú serás más dulce con los otros" (VII,63): CI 240. Cf. Conf. XI,2,4.

Es una verdad evidente que: "Los hombres han sido hechos los unos para los otros: instrúyelos o sopórtalos" (VIII,59): CI 241. Pero, según M. Aurelio, algunos hombres incorregibles: "es necesario que haya en este mundo" (IX,42,2): CI 241. Hay que corregir sin humillar. "El hombre que es bueno, sin doblez, que es dulce, tiene sus cualidades en los ojos y esto no escapa a nadie": XI,15. "La bondad es invencible, si es sincera, sin sonrisa burlona y sin afectación" (XI,18,15): CI 242.

Es más viril el que es más humano: "Una sola cosa tiene valor aquí abajo: pasar la vida en la verdad y la justicia siendo benévolo con los mentirosos y los injustos": VI,47,6. Pero que no te amarguen la vida los que estorban tu progreso hacia la razón: XI,9. "Lo propio del hombre, es amar también a los que cometen faltas. Esto se realizará si tú tomas conciencia de que todos son de tu misma raza y que pecan por ignorancia y contra su voluntad" (VII, 22,1-1): CI 244.

"Hemos sido hechos para cooperar" (VII,1,3); "al hacer el bien tú te haces bien a ti mismo": VII,13. Es un sentimiento de "cuerpo místico", el matrimonio entre el cielo y la tierra, "los procesos naturales son siempre procesos de unión y de amor": "Yo digo Mundo: y yo amo también Contigo" (X,21): CI 246. En el cristianismo el amor se personaliza: Mt 25. "El logos, a los ojos del cristiano se encarna en Jesús y el cristiano ve en su prójimo a Jesús": CI 246. Pero, el estoicismo es también una doctrina de amor. Como dice Séneca: "Ninguna escuela tiene más bondad y dulzura, ninguna tiene más amor a los hombres, más atención al bien común. El fin que él nos asigna, es ser útil, ayudar a los otros y cuidar no solamente de sí mismo sino también de todos en general y de cada uno en particular" (De la clemencia, II,3,3): C I247.

\section{4.- Las virtudes y la alegría}

Los Pensamientos se organizan con una estructura y un sistema ternario que había sido desarrollado y ordenado por Epicteto: CI 249. Son los tres temas de la filosofía (física, ética y lógica), los tres potencias del alma, y 
tres formas de realidad que son: el destino, la comunidad de los seres racionales y la facultad del conocimiento y del juicio: CI 249. "Para los estoicos el valor supremo es la areté que no se funda en la nobleza guerrera sino en la nobleza del alma que es la pureza de intención": CI 250. La injusticia y la mentira es una impiedad contra la diosa Naturaleza (CI 251), pues cada uno recibe de ella una disposición a la verdad que por negligencia no realiza: CI 252.

Por la acción se nos impone ayudar a los hombres, por el juicio distinguir lo verdadero de lo falso, y por el deseo aceptar la suerte que nos reserva la Naturaleza universal: CI 252-3. Estas virtudes aportan al alma la verdadera alegría porque le aportan "lo único necesario, el único valor absoluto". El verdadero gozo consiste en vivir conforme a la naturaleza (CI 256) y servir al bien común. "La felicidad del hombre consiste en hacer lo que es propio del hombre. Y, lo propio del hombre es la benevolencia con los otros hombres, con sus parientes, el desprecio de las emociones sensibles, la crítica de las representaciones engañosas, la contemplación de la Naturaleza universal y de todo lo que acontece conforme a su voluntad" (VIII,26): CI 257.

El gozo es el signo de la perfección de la acción, la experiencia de participar en un organismo vivo, de ser miembro de un cuerpo de seres razonables: CI 257. "Este gozo que procura la acción realizada conforme a la Naturaleza es una comunión en el amor de la Naturaleza por el Todo que ella produce y en el amor recíproco de las partes del Todo": CI 257. Ese es un camino divino, un buen camino, un camino recto enraizado en la tendencia profunda del ser vivo al amor: CI 258.

En resumen, M. Aurelio en sus Pensamientos, nos ofrece un escrito sobre sí mismo. "No se trata de una auto-justificación sino, más bien de una autocrítica y de una tras-formación de sí": CI 267. Él mismo nos presenta su género literario cuando evoca "el retiro espiritual en sí mismo". Es una preparación a la muerte, por eso evoca a los grandes hombres que también han muerto: CI 293. Y, son como unas Confesiones, más al estilo de Agustín que de Rousseau, "una acción de gracias por los dones recibidos de los dioses y de los hombres": CI 296.

$\mathrm{Y}$ así nos dice: " $\mathrm{El}$ 'hombre de bien' que prefiere su daimon interior a todo lo demás, del cual es, en cierto modo, su ministro y servidor, alcanza el nivel supremo de la felicidad humana que consiste en actuar conforme a la recta razón" (III,7,2): CI 282-3. Entonces: "Nada me sucederá que no sea conforme a la Naturaleza del Todo. Depende de mí no hacer nada que sea contrario a mi dios y a mi daimon" (V,10,6): CI 284. Así, se ha podido definir la vida moral como "una vida con los dioses" (V,27): CI 284. Las cosas están sometidas a una rápida metamorfosis (VII,10,18,19,23,25), pues la 
Naturaleza es creadora de nuevos seres (VIII,50,18), pero hay que tomar conciencia de lo más noble y divino que hay en nosotros: CI 291.

\section{Una nueva mirada a las Meditaciones de Marco Aurelio}

Vamos a recoger algunos Pensamientos más de $\mathrm{M}$. Aurelio que pueden completar la exposición de Hadot, pues como dice E. Bianchi: "Es significativo que en el monacato medieval, uno de los autores más leídos, sobre todo en el ambiente cartujo, fuera Marco Aurelio. Guigo el Cartujano redactó sus Pensamientos, casi calcando los Pensamientos de Marco Aurelio. El monje auténtico es el que busca a Dios, pero precisamente en la búsqueda de Dios va buscando al hombre y su humanización"9.

Así, advierte ese gran pensador: “¡Breve es la vida para cada uno! Tú prácticamente, la has consumido sin respetar el alma que te pertenece, y sin embargo, haces depender tu buena fortuna del alma de los otros"10.

Con todo, la vida huye. "¿Qué, pues, puede darnos compañía? Única y exclusivamente la filosofía. Y ésta consiste en preservar el guía interior, exento de ultrajes y de daño, dueño de placeres y penas, sin hacer nada al azar, sin valerse de la mentira ni de la hipocresía, al margen de lo que otro haga o deje de hacer; más aún, aceptando lo que acontece y se le asigna, como procediendo de aquel lugar de donde él mismo ha venido. Y sobre todo, aguardando la muerte con pensamiento favorable, en la convicción de que ésta no es otra cosa que disolución de los elementos de que está compuesto cada ser vivo (...). Pues esto es conforme a la naturaleza, y nada es malo si es conforme a la naturaleza": MA 2,17.

"Porque el hombre de estas características que ya no demora el situarse como entre los mejores, se convierte en sacerdote y servidor de los dioses, puesto al servicio también de la divinidad que se asienta en su interior, todo lo cual le inmuniza contra los placeres, le hace invulnerable a todo dolor, intocable respecto a todo exceso, insensible a toda maldad, atleta de la más excelsa lucha, lucha que se entabla para no ser abatido por ninguna pasión, impregnado a fondo de justicia, apegado, con toda su alma, a los acontecimientos y a todo lo que se le ha asignado; y raramente, a no ser por una gran necesidad y en vista del bien común, cavila lo que dice, hace o proyecta otra persona (...) Tiene también presente que todos los seres raciona-

\footnotetext{
9 BIANCHI, Enzo, Otra forma de vivir. Paradojas de la vida monástica. Narcea, Madrid 2008,90

10 Marco Aurelio, Meditaciones. Gredos, Madrid 1983, 2,6. En adelante MA.
} 
les están emparentados y que preocuparse de todos los hombres está de acuerdo con la naturaleza humana": MA 3,4.

"Porque la persona que prefiere, ante todo, su propia razón, su divinidad y los ritos del culto debido a la excelencia de ésta, no representa tragedias, no gime, no precisará soledad ni tampoco aglomeraciones de gente. (Y) lo que es más importante: vivirá sin perseguir ni huir": MA 3,7.

"Venera la facultad intelectiva. En ella radica todo, para que no se halle jamás en tu guía interior una opinión inconsecuente con la naturaleza y con la disposición del ser racional. Esta, en efecto, garantiza la ausencia de precipitación, la familiaridad con los hombres y la conformidad con los dioses": MA 3,9.

"Pues no llevarás a feliz término ninguna cosa humana sin relacionarla al mismo tiempo con las divinas, ni tampoco al revés". Es propio del hombre excelente abrazar y amar lo que le viene. "Y el no confundir ni perturbar jamás al Dios que tiene la morada dentro de su pecho con una multitud de imágenes, antes bien, velar para conservarse propicio, sumiso, disciplinadamente, al Dios, sin mencionar una palabra contraria a la verdad, sin hacer nada contrario a la justicia. Y si todos los hombres desconfían de él, de que vive con sencillez, modestia y buen ánimo, no por ello se molesta con ninguno, ni se desvía del camino trazado que le lleva al fin de su vida, objetivo hacia el cual debe encaminarse, puro, tranquilo, liberado, sin violencia y en armonía con su propio destino": MA 3,16.

"El dueño interior, cuando está de acuerdo con la naturaleza, adopta, respecto a los acontecimientos, una actitud tal que siempre, y con facilidad, puede adaptarse a las posibilidades que se le dan": MA 4,1.

"Se buscan retiros en el campo, en la costa y en el monte. Tú también sueles anhelar tales retiros. Pero todo eso es de lo más vulgar, porque puedes, en el momento que te apetezca, retirarte en ti mismo (...) Concédete, pues, sin pausa, este retiro y recupérate (...) Te resta, pues, tenlo presente, el refugio que se halla en este diminuto campo de ti mismo": MA 4,3.

"Si la inteligencia nos es común, también la razón, según la cual somos racionales, nos es común. Admitido eso, la razón que ordena lo que debe hacerse o evitarse, también es común. Concedido eso, también la ley es común. Convenido eso, somos ciudadanos. Aceptado eso, participamos de una ciudadanía. Si eso es así el mundo es como una ciudad. Pues, ¿de qué otra común ciudadanía se podrá afirmar que participa todo el género humano? De allí, de esta común ciudad, proceden tanto la inteligencia misma como la razón y la ley": MA 4,4 . Para S. Agustín la ciudad de Dios son sus ciudadanos.

"Por lo demás, todo lo que es bello en cierto modo, bello es por sí mismo, y termina en sí mismo sin considerar el elogio como parte de sí 
mismo. En consecuencia, ni se empeora ni se mejora el objeto que se alaba": MA 4,20 (S. Agustín in ps. 99,12: La crítica o la alabanza de los otros ni nos mejora ni nos empeora11.

Suprimir lo innecesario aporta ocio y tranquilidad: "En consecuencia, es preciso recapacitar personalmente en cada cosa: ¿No estará esto entre lo que no es necesario? Y no sólo es preciso eliminar las actividades innecesarias sino incluso las imaginaciones. De esta manera, dejarán de acompañarlas actividades superfluas": MA 4,24. Según la Regla de S. Agustín: "Más vale necesitar poco que tener mucho", y según Horacio, en sus Saturae: "una sacra auri fames, destroza el corazón del hombre".

"Piensa, por ejemplo, en los tiempos de Vespasiano. Verás siempre las mismas cosas: personas que se casan, crían hijos, enferman, mueren, hacen la guerra, celebran fiestas, comercian, cultivan la tierra, adulan, son orgullosos, recelan, conspiran, desean que algunos mueran, murmuran contra la situación presente, aman, atesoran, ambicionan los consulados, los poderes reales. Pues bien, la vida de aquellos ya no existe en ninguna parte": MA 4,32. Dice el Evangelio: Será como en los tiempos de... trabajaban, se casaban...

"Concibe sin cesar el mundo como un ser viviente único, que contiene una sola sustancia y un alma única, y cómo todo se refiere a una sola facultad de sentir, la suya, y cómo todo lo hace con un sólo impulso, y cómo todo es responsable solidariamente de todo lo que acontece, y cuál es la trama y contextura": MA 4,40.

“No ves que los arbustos, los pajarillos, las hormigas, las arañas, las abejas, cumplen su función propia, contribuyendo por su cuenta al orden del mundo? Y tú entonces, ¿rehúsas hacer lo que es propio del hombre? ¿No persigues con ahínco lo que está de acuerdo con tu naturaleza?: MA 5. San Agustín se queja en Confes. VI,9-10, de que las criaturas cumplen su papel, el hombre no.

"Y en tus actividades no sólo no cumples lo suficiente, sino que te quedas por debajo de tus posibilidades. Por consiguiente, no te amas a ti mismo, porque ciertamente en aquel caso amarías tu naturaleza y su propósito. Otros que aman su profesión, se consumen en el ejercicio del trabajo idóneo, sin lavarse ni comer (...) Y a ti ¿te parecen las actividades comunitarias desprovistas de valor y merecedoras de menor atención?": MA 5,1. Según Agustín, es virtuoso el que ama las cosas comunes más que las propias: Regla 5,31. Pues, "es propio del ser sociable, manifiesta, darse cuenta de que obra de acuerdo y conforme al bien común": MA 5,6.

11 Rubio BARdón, Pedro, Recordar, nº 1217. 
Por lo demás: "Donde es posible vivir, también allí se puede vivir bien (...) Naturalmente, el bien de un ser racional es la comunidad. Que efectivamente hemos nacido para vivir en comunidad, tiempo ha que ha sido demostrado": MA 5,16.

"Respeta lo más excelente que hay en el mundo; y eso es lo que se sirve de todo y cuida de todo. E igualmente estima lo más excelente que en ti reside; y eso es del mismo género que aquello. Y en ti lo que aprovecha a los demás es eso y eso es lo que gobierna la vida": MA 5,21.

"Sea el guía interior y soberano de tu alma una parte indiferente al movimiento, suave o áspero, de la carne, y no se mezcle, sino que se circunscriba, y limite aquellas pasiones a los miembros": MA 5,26. Así, como en los relatos de A. Gelio, Mónica se impone al temor de la tempestad: Confes. VI,1,1. La vida humana es: "'Convivir con los dioses'. Y convive con los dioses aquel que constantemente les demuestra que su alma está satisfecha con la parte que le ha sido asignada, y hace todo cuanto quiere el genio divino, que, en calidad de protector y guía, fracción de sí mismo, asignó Zeus a cada uno. Y esta divinidad es la inteligencia y razón de cada uno": MA 5,27. La razón es un gran don de Dios según S. Agustín.

¿Qué es un alma sabia?: "La que conoce el principio y el fin y la razón que abarca la sustancia del conjunto y que, a lo largo de todo la eternidad, gobierna el Todo de acuerdo con ciclos determinados": MA 5,32. "Puedes encauzar bien la vida, si eres capaz de caminar por la senda buena, si eres capaz de pensar y actuar con método. Estas dos cosas son comunes al alma de Dios, a la del hombre, y a todo ser racional: el no ser obstaculizado por otro, el cifrar el bien en una disposición y actuación justa y el poner fin a tu aspiración aquí": MA 5,34. "Pero ser afortunado es haberte asignado un buen lote; $y$ un buen lote son las buenas tendencias del alma, buenos impulsos, buenas acciones": MA 5,36.

"Mira el interior; que de ninguna cosa te escape ni su peculiar cualidad ni su mérito": MA 6,3. "El guía interior es lo que se despierta a sí mismo, se gira y se hace a sí mismo como quiere, y hace que todo acontecimiento le aparezca tal como él quiere": MA 6,8. S. Agustín busca y ama el Hombre Interior...

“ Cuidado! No te conviertas en un César, no te tiñas siquiera, porque suele ocurrir. Mantente, por tanto, sencillo, bueno, puro, respetable, sin arrogancia, amigo de lo justo, piadoso, benévolo, afable, firme en el cumplimiento del deber. Lucha para conservarte tal cual la filosofía ha querido hacerte. Respeta a los dioses, ayuda a salvar a los hombres. Breve es la vida. El único fruto de la vida terrena es una piadosa disposición y actos útiles a la comunidad": MA 6,30. 
"Vuelve en ti y reanímate, y una vez que hayas salido de tu sueño y hayas comprendido que te turbaban pesadillas, nuevamente despierto, mira esas cosas como mirabas aquéllas": MA 6,31. "Amóldate a las cosas que te han tocado en suerte; y a los hombres con los que te ha tocado en suerte vivir, ámalos, pero de verdad": MA 6,39. "Cuanto acontece a cada uno, importa al conjunto. Esto debería bastar. Pero además, en general, verás, si te has fijado atentamente, que lo que es útil a un hombre, lo es también a otros hombres": MA 6,45. "Lo que no beneficia al enjambre, tampoco beneficia a la abeja": MA 6,54. "Porque lo que estoy haciendo por mí mismo, o en colaboración con otro, debe tender, exclusivamente, al beneficio y buena armonía de la comunidad": MA 7,5.

"Todas la cosas se hallan entrelazadas entre sí y su común vínculo es sagrado y casi ninguna es extraña a la otra, porque todas están coordinadas y contribuyen al orden del mismo mundo. Que uno es el mundo, compuesto de todas las cosas; uno el dios que se extiende a través de todas ellas, única la sustancia, única la ley, una sola razón común de todos los seres inteligentes, una también la verdad, porque también una es la perfección de los seres del mismo género y de los seres que participan de la misma razón": MA 7,9. S. Pablo habla de un solo cuerpo, un solo Señor, una sola fe, etc.: Ef 4,5.

"Como existen los miembros del cuerpo en los individuos, también los seres racionales han sido constituidos, por este motivo, para una idéntica colaboración, aunque en seres diferentes. Y más se te ocurrirá este pensamiento si muchas veces hicieras esta reflexión contigo mismo": MA 7,13. Los cristianos son un solo cuerpo y un solo espíritu, según $\mathrm{Rm} 12,4-8$ y $1^{\mathrm{a}}$ Cor 12, 1-31.

Como el deber del oro es ser oro y el de la esmeralda ser esmeralda: "Dígase o hágase lo que quiera, mi deber es ser bueno": MA 7,15. "Mi guía interior no se altera por sí mismo; quiero decir, no se asusta ni se aflige": MA 7,16. "Recógete en ti mismo. El guía interior racional puede, por naturaleza, bastarse a sí mismo practicando la justicia, y, según eso mismo, conservando la calma": MA 7,28. "No vayas afuera sino vuélvete a ti mismo, porque en el interior del hombre habita la verdad", dice S. Agustín.

"Haz resplandecer en ti la sencillez, el pudor y la indiferencia en lo relativo a lo que es intermedio entre la virtud y el vicio. Ama al género humano. Sigue a Dios": MA 7,31.

Platón en Gorgias 512 d: "Pero mi buen amigo, mira si la nobleza y la bondad no serán otra cosa que salvar a los demás y salvarte a ti mismo": MA 7,46.

Eurípides, Crisipo: “'Lo que ha nacido de la tierra a la tierra retorna; lo que ha germinado de la semilla etérea vuelve nuevamente a la bóveda 
celeste"”: MA 7,50. "Si amas la tierra eres tierra, si amas al cielo eres cielo"..., dice S. Agustín.

"Cada uno debe hacer lo que corresponde a su constitución (...) En consecuencia, lo que prevalece en la constitución humana es la sociabilidad": MA 7,55): "Socialis est vita sanctorum", dice Agustín en La ciudad de Dios.

"Cava en tu interior. Dentro se halla la fuente del bien, y es una fuente capaz de brotar continuamente, si no dejas de excavar": MA 7,59. S. Agustín insiste: "In te ipsum reddi, in interiore hominis habita veritas"...

"Toda alma, afirma (Platón) se ve privada contra su voluntad de la verdad". Igualmente también de la justicia, de la prudencia, de la benevolencia y de toda virtud semejante. $\mathrm{Y}$ es muy necesario tenerlo presente en todo momento, y así serás más condescendiente con todos: MA 7,63. Según Agustín: Sea duro con vosotros el que no sabe lo que cuesta la virtud...

"'Para mí el presente es siempre materia de virtud racional, social y, en suma, materia de arte humano y divino'. Porque todo lo que acontece se hace familiar a Dios o al hombre, y ni es nuevo ni es difícil de manejar, sino conocido y fácil de manejar": MA 7,68.

No te preocupe la 'masa pastosa' ni la vanagloria sino la vida feliz. "Y sea suficiente para ti vivir el resto de tu vida, dure lo que dure, como tu naturaleza quiere": MA 8,1. "Toda naturaleza está satisfecha consigo misma cuando sigue el buen camino. Y sigue el buen camino la naturaleza racional cuando en sus imaginaciones no da su asentimiento ni a lo falso ni a lo incierto y, en cambio, encauza sus instintos sólo a acciones útiles a la comunidad, cuando se dedica a desear y detestar aquellas cosas que dependen exclusivamente de nosotros, y abraza todo lo que le asigna la naturaleza común": MA 8,7.

"Siempre que de mal talante despiertes de tu sueño, recuerda que está de acuerdo con tu constitución y con tu naturaleza humana corresponder con acciones útiles a la comunidad, y que dormir es también común a los seres irracionales": MA 8,12.

Para M. Aurelio, la faltas de ira son más comprensibles que las de concupiscencia, porque el hombre airado "se ha visto forzado a montar en cólera por dolor; el segundo se ha lanzado a la injusticia por concupiscencia": MA 2,10.

Pero: "La dicha del hombre consiste en hacer lo que es propio del hombre. Y es propio del hombre el trato benevolente con sus semejantes, el menosprecio de los movimientos de los sentidos, el discernir las ideas que inspiran crédito, la contemplación de la naturaleza del conjunto universal y de las cosas que se producen de acuerdo con ella": MA 8,26.

A veces hay miembros amputados del cuerpo. Y: "Algo parecido hace consigo, en la medida que de él depende, el que no se conforma con lo que 
acaece y se separa, o el que hace algo contrario al bien común (...) A ningún otro miembro permitió Dios separarse y desgajarse, para reunirse de nuevo. Pero examina la bondad con la que Dios ha honrado al hombre. Pues en sus manos dejó la posibilidad de no separarse absolutamente del conjunto universal y, una vez separado, la de reunirse, combinarse en un todo y recobrar la posición de miembro": MA 8,34.

"Uno se alegra de una manera, otro de otra. En cuanto a mí, si tengo sano mi guía interior, me alegro de no rechazar a ningún hombre ni nada de lo que a los hombres acontece; antes bien, de mirar todas las cosas con ojos benévolos y aceptando y usando cada cosa de acuerdo con su mérito": MA 8,43. Agustín nos invita a un uti et frui adecuado de las cosas...

Por lo demás, MA advierte: “Ten presente que el guía interior llega a ser inexpugnable, siempre, que, concentrado en sí mismo, se conforme absteniéndose de hacer lo que no quiere aunque se oponga sin razón": MA 8,567. Y: "Ni seas negligente en tus acciones, ni embrolles en tus conversaciones, ni en tus imaginaciones andes sin rumbo, ni, en suma, constriñas tu alma o te disperses, ni en el transcurso de la vida estés excesivamente ocupado": MA 8,51.

"Los hombres han nacido los unos para los otros. Instrúyelos o sopórtalos": MA 8,59. "Introdúcete en la guía interior de cada uno y permite también a otro cualquiera que penetre en tu guía interior": MA 8,61.

"El que comete injusticia es impío (...) Más todavía, esta divinidad recibe el nombre de Verdad y es la causa primera de todas las verdades. En consecuencia, el hombre que miente voluntariamente es impío, en cuanto que al engañar comete injusticia": MA 9,1.

El vicio es una peste, la peste humana: "El que peca, peca contra sí mismo; el que comete una injusticia, contra sí la comete, y a sí mismo se daña": MA 9,4.

"Una sola alma ha sido distribuida entre los animales irracionales, un alma inteligente ha sido dividida entre los seres racionales, igualmente una es la tierra de todos los seres terrestres y con una sola luz vemos y uno es el aire que respiramos todos cuantos estamos dotados de vista y de vida": MA 9,8 .

La tierra tiende a la tierra, el fuego hacia el cielo, los seres dotados de inteligencia 'han olvidado ahora el afán y la inclinación mutua'. "Pero a pesar de sus intentos de huida, son reagrupados, porque prevalece (Heráclito ff. $114 \mathrm{D}$ ) la naturaleza. Se encontrara más rápidamente un objeto terrestre sin conexión alguna con un objeto terrestre que un hombre separado del hombre": MA 9,9. Cada cosa tiende a su lugar, por el peso del amor, dice Agustín... 
"Penetra en su guía interior, y verás qué jueces temes, qué clase de jueces son respecto a sí mismos": MA 9,18. S. Agustín nos dice: Enfréntate a ti mismo, y dite la verdad: "Multi enim bene ambulant pedibus, et male ambulant moribus. Aliquando enim ipsi bene ambulantes, praeter viam currunt. Invenies quippe homines bene viventes, et non christianos. Bene currunt: sed in via non currunt. Quanto plus currunt, plus errant (...) Si autem non tenent viam, quantumvis bene ambulent, heu quam dolendum est! Melius est enim in via claudicare, quam praeter viam fortiter ambulare": Sermón 141,4 .

¿Quién puede hacer afirmaciones respecto de las cosas?: "El guía interior": MA 9,15. "Corre al encuentro de tu guía interior, del guía del conjunto universal y del de éste. Del tuyo para que hagas de él una justa inteligencia; del que corresponde al conjunto universal, para que rememores de quién formas parte; del de éste, para que sepas si existe ignorancia o reflexión en él, y, al mismo tiempo, consideres que es tu pariente": MA 9,22.

"Al igual que tú mismo eres un miembro complementario del sistema social, así también toda tu actividad sea complemento de la vida social. Por consiguiente, toda actividad tuya que no se relacione, de cerca o de lejos, con el fin común, trastorna la vida y no permite que exista unidad, y es revolucionaria, de igual modo que en el pueblo el que retira su aportación personal a la armonía común": MA 9,23.

El fin del justo es "obrar de acuerdo con el bien común, en la convicción de que esta tarea es acorde con tu naturaleza": MA 9,31. Si tu guía está perturbado, "dile a tu guía interior: 'Has muerto, has sido destruido, te has convertido en bestia, interpretas un papel, formas parte de un rebaño, pastas"": MA 9,39.

“¿Serás tú algún día tal, que puedas convivir como ciudadano, con los dioses y con los hombres, hasta el extremo de no hacerles ninguna censura ni ser condenado por ellos?": MA 10,1. Y, como hombre seré feliz: "en la medida que tengo cierto parentesco con la parte de mi misma condición, nada contrario a la comunidad ejecutará, sino que más bien mi objetivo tenderá hacia mis semejantes, y hacia lo que es provechoso a la comunidad encaminaré todos mis esfuerzos, absteniéndome de lo contrario": MA 10,6.

"Después de asignarte esos nombres: bueno, reservado, veraz, prudente, condescendiente, magnánimo, procura no cambiar nunca de nombre, y, si perdieras dichos nombres, emprende su búsqueda a toda prisa... para recordar estos nombres, gran colaboración te proporcionará el recuerdo de los dioses" (...) y así "serás diferente y entrarás en una vida nueva": MA 10,8. La bondad, la verdad, la amistad, todo eso es Cristo y más, dice S. Agustín, In Jn, 26,4-5. 
“QQué significa para mí guía interior?, ¿y qué hago de él ahora, y para qué lo utilizo actualmente? ¿Por ventura está vacío de inteligencia, desvinculado y arrancado de la comunidad, fundido y mezclado con la carne, hasta el punto de poder modificarse con ésta?": MA 10,24.

"El que rehúye a su señor es un desertor. La ley es nuestro señor, y el que la transgrede es un desertor": MA 10,25.

"A nadie le sea posible decir de ti con verdad que no eres hombre sencillo y bueno": MA 10,32. “¿He realizado algo útil a la comunidad? En consecuencia, me he beneficiado. Salga siempre a tu encuentro y ten a mano esta máxima, y nunca la abandones": MA 11,4. "¿Cuál es tu oficio? Ser

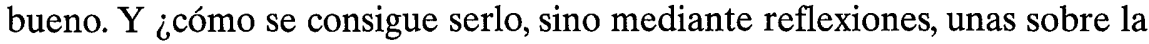
naturaleza del conjunto universal, y otras, sobre la constitución peculiar del hombre?": MA 11,5.

Como la rama cortada de otra queda separada del árbol. "De igual modo, un hombre, al quedar separado de un hombre, ha quedado excluido de la comunidad entera. En efecto, corta otro la rama: sin embargo, el hombre se separa él mismo de su vecino cuando le odia y siente aversión. E ignora que se ha cercenado al mismo tiempo de la sociedad entera": MA 11,8 (Jn15). Dice S. Agustín en la Regla 6,2: El que no pide perdón, está separado por el odio, y "sin motivo está en el monasterio aunque no sea expulsado".

No debemos dejarnos desviar de la benevolencia ni de la mansedumbre: "Porque es también signo de debilidad el enojarse con ellos, al igual que el renunciar a actuar y ceder por miedo, pues ambos son igualmente desertores, el que tiembla, y el que se hace extraño a su pariente y amigo por naturaleza": MA 11,9.

"La esfera del alma es semejante a sí misma, siempre que, ni se extienda en busca de algo exterior, ni se repliegue hacia dentro, ni se disemine, ni se condense, sino que brille con una luz gracias a la cual vea la verdad de todas las cosas y la suya interior": MA 11,12. "Porque, ¿qué mal te sobrevendrá si haces ahora lo que es propio de tu naturaleza, y aceptas lo que es oportuno ahora a la naturaleza del conjunto universal, tú, un hombre que aspira conseguir por el medio que sea lo que conviene a la comunidad?": MA 11,13.

"Nada es más abominable que la amistad del lobo. Por encima de todo evita eso. El hombre bueno, sencillo y benévolo tiene estas cualidades en los ojos y no se le ocultan": MA 11,15.

"En noveno lugar, que la benevolencia sería invencible si fuera noble y no burlona ni hipócrita. Porque, ¿qué te haría el hombre más insolente, si fueras benévolo con él y si, dada la ocasión, le exhortaras con dulzura y le 
aleccionaras apaciblemente en el preciso momento en que trata de hacerte daño? 'No hijo; hemos nacido para otra cosa. No temo que me dañes, eres tú quién te perjudicas, hijo"”: MA 11,18. Como dice el salmo: "Qui diligit iniquitatem odit animam suam"...

Es propio de los malvados hacer mal. "Sin embargo, convenir què se comporten así con otras personas y pretender que no falten contigo, es algo absurdo y propio de tirano": MA 11,18.

Hay que guardar de cuatro cosas, al guía interior, y procurar apartarlas en estos términos: "Esta idea no es necesaria, esta es disgregadora de la sociedad, esta otra que vas a manifestar no surge de ti mismo' (...) también hay que guardarse de que "la parte más divina que se halla en ti, esté sometida e inclinada a la parte menos valiosa y mortal, la de tu cuerpo y sus rudos placeres": MA 11,19.

"Quien no tiene un solo e idéntico objetivo en la vida, es imposible que persista durante toda ella único e idéntico": MA 11,21. "Todos los objetivos que deseas alcanzar en tu progreso puedes ya tenerlos si no te los regateas a ti mismo y por recelos. Es decir: caso de que abandones todo el pasado, confíes a la providencia el porvenir y endereces el presente hacia la piedad y la justicia exclusivamente (...). Si, pues, en el momento en que llegues a la salida, dejas todo lo demás y honras exclusivamente a tu guía interior y la divinidad ubicada en ti (...) serás un hombre digno del mundo que te engendró": MA 12,1.

"Dios ve todos los guías interiores desnudos de sus envolturas materiales, de sus cortezas y de sus impurezas: porque gracias a su inteligencia exclusiva, tiene contacto sólo con las cosas que han derivado y dimanado de él en sus principios. Y si tú también te acostumbras a hacer eso, acabarás con muchas de tus distracciones": MA 12,2. "Si separas de tu guía interior todo lo que depende de la pasión, lo futuro y lo pasado (...) y te ocupas en vivir exclusivamente lo que vives, a saber, el presente, podrás al menos vivir el resto de tu vida hasta la muerte, sin turbación, benévolo y propicio con tu divinidad interior": MA 12,2?

"¡Qué privilegio tiene el hombre de no hacer otra cosa sino lo que Dios va a elogiar, y aceptar todo lo que Dios le asigne, lo consecuente a la naturaleza!": MA 12,11. Por eso, se pide al hombre: "Date cuenta de una vez que algo más poderoso y divino posees en tu propio interior que lo que provoca las pasiones y que lo que, en suma, te agita a modo de marioneta": MA 12,19 .

"En primer lugar, no hacer nada al azar, ni tampoco sin un objetivo final. En segundo lugar, no encauzar tus acciones a otro fin que no sea el bien común": MA 12,20. 
"Así, el que se comporta de acuerdo con Dios en todo, es inspirado por un hálito divino y es llevado, gracias a su reflexión, a sus mismos objetivos": MA 12,23. Por eso, cada uno ha de pensar: “¿Qué pretendes? ¿Seguir viviendo? ¿Percibir las sensaciones, los instintos? ¿Crecer? ¿Cesar de nuevo? ¿Utilizar la palabra? ¿Pensar? ¿Qué cosa entre estas te parece que vale la pena echar de menos? Y si cada una de éstas te parece bien despreciable, inclínate finalmente a ser sumiso a la razón y a Dios?": MA 12,31.

En resumen, es preciso pensar: “¿Cómo se sirve de ti el guía interior? Que en eso radica todo. Y lo demás, dependa o no de tu libre elección, es cadáver y humo": MA 12,33.

\section{La filosofía como forma de vida en la teoría y la práctica}

Para Hadot: "El discurso filosófico se origina por tanto en una elección de vida y en una opción existencial, y no a la inversa"12. Y, se hace en una comunidad filosófica. Por lo demás: "el discurso filosófico forma parte del modo de vida": FA 15. Así: "el verdadero saber es finalmente un saber hacer, y el verdadero saber es saber hacer el bien": FA 30. Y esto lleva a ver: "lo que es, lo que será, lo que fue": FA 31-32.

En todas las escuelas antiguas, la filosofía aparecerá: "como un cierto discurso vinculado con un modo de vida y como un modo de vida vinculado con cierto discurso": FA36. Por lo demás: "el más sabio de los seres humanos es "aquel que sabe que no vale nada en lo que se refiere al saber" (Apología, 23b): FA 38.

Para Sócrates: "no hay más que un bien, un solo valor, la voluntad de hacer el bien": FA 48. Por eso recomienda el examen de la propia vida, pues: "una vida sin examen no tiene objeto vivirla para el hombre": FA 48. Para Sócrates, la filosofía es una sólida formación del juicio para "tomar decisiones razonables", y aprender a tratar bien los temas elevados. "Así, la filosofía es, para él, indisolublemente, el arte de decir bien y de vivir bien": FA 64.

En el Banquete de Platón, el amor se muestra como creador y fecundo, sea en el cuerpo o la inteligencia. "Pero la forma más elevada de inteligencia es el dominio de sí mismo y la justicia, y se ejerce en la organización de las ciudades o de las otras instituciones": FA 67 . Hadot cree que la fundación de la Academia de Platón se inspira en la forma de vida socrática y

12 Hadot, Pierre, ¿Qué es la Filosofía Antigua? FCE, Madrid 1998, 13. En adelante FA. 
pitagórica: FA 70. Del mismo modo, la educación "se hará en el seno de una comunidad, de un grupo, de un círculo de amigos, donde reinará una atmósfera de amor sublimado": FA 72. El mismo diálogo de platónico, es, según Mittelstrass, una "forma de vida" (FA 77) basada en "la sublimación del amor": FA 82. Aquí encontramos: "el poder educador de la presencia amorosa", pues: "No aprendemos más que de quien amamos", según Goethe, Conversaciones con Eckermann, 12.5.1825: FA 83.

Por todo eso, se recomienda: "seguir esta 'senda', esta 'maravillosa senda", "hacer más caso a la virtud que al placer", y "vivir cada día a fin de volverse lo más posible dueño de sí": FA 79. Y: "dormir poco", "conservar la tranquilidad en la desgracia sin rebelarse" (República 604 b-c.), separar el alma del cuerpo y "liberarla de la dispersión y de la distracción que le impone el cuerpo": FA 80.

Platón mismo, en la carta VII, dice que se vio impulsado hacia la filosofía, pues: "sólo a su luz, se puede reconocer en dónde radica la justicia en la vida pública y en la vida privada": FA 71. Según P. Rabbow, hay una gran oposición entre: "el modo de vida del filósofo, que consiste en 'volverse justo y santo en la claridad de la inteligencia' que por ello es al mismo tiempo ciencia y virtud, y el modo de vida de los no filósofos": FA 82. Por eso, dice Goldschmidt que: "los diálogos no fueron escritos para 'informar' sino para 'formar"”: FA 86. Y así: "El saber platónico, a semejanza del saber socrático, es ante todo un saber de los valores": FA 88.

Así, en toda la $\mathrm{H}^{\mathrm{a}}$ de la Filosofía, encontramos: "por una parte, la elección y la práctica de un modo de vida; por la otra, un discurso filosófico, que, al mismo tiempo, forma parte integrante de este modo de vida y hace explícitas las presuposiciones teóricas implicadas en este modo de vida": FA 89. Pero este discurso nunca explica del todo lo experimentado en el diálogo y en el deseo humano del Bien.

En Aristóteles, "la dicha filosófica se encuentra en la "vida según el entendimiento', que se sitúa en la excelencia y la virtud más elevada del hombre, correspondiendo su parte más alta, a la mente, y sustraída de los inconvenientes que conlleva la vida activa": FA 91. El que se consagra a esta vida sólo depende de sí mismo, y estar consigo mismo es su mejor recompensa, evita perturbaciones y lleva al desprendimiento de preocupaciones materiales, conduce a la felicidad humana y algo más, pues: "el hombre no viviría de esta manera en cuanto hombre, sino en cuanto que hay algo divino en él" (Etica a Nicómaco, X,1177b27): FA 92. Así: "La mente es nuestro yo en la medida en que representa lo que decide y lo que es mejor": FA 92.

Y, la sabiduría es: "como un estado divino, por consiguiente inasequible al hombre, y sin embargo el filó-sofo, el que ama la sabiduría, lo deseaba": 
FA 93. La felicidad filosófica suprema es: "la contemplación el Intelecto divino", que sólo en algunos momentos se da en el hombre: FA 93.

En efecto, para Aristóteles, la praxis teorética es elegir "el conocimiento por sí mismo sin perseguir ningún otro interés particular y egoísta que sería ajeno al conocimiento. Es una ética del desinterés y de la objetividad" (FA 95), un intento de elevarse a la sabiduría, más divina que humana, pues: "sólo Dios puede gozar de ese privilegio": Metafísica I, 982 b 30: FA 100.

Del mismo modo, por el conocimiento de la naturaleza admiramos su vida interior. "Según Aristóteles, presentimos así en la naturaleza una presencia divina. En el sentido de la frase de Heráclito que evoca", ("también aquí se encuentran los dioses"): FA 98. Así: "La filosofía es pues, para Aristóteles, como para Platón, al mismo tiempo un estilo de vida y un modo de discurso": FA 104. Y a pesar de las dificultades que señalan tanto Epicuro como M. Aurelio: "En general, los filósofos nunca renunciaron a la esperanza de cambiar la sociedad, por lo menos mediante el ejemplo de su vida": FA 108.

Además, tanto en la Academia como en el Liceo como en la escuela Epicuro se tomaban alimentos en común a intervalos regulares, tal vez por eso había un cargo responsable, al efecto, que todos debían asumir por turnos durante varios días: FA 90 y 114.

Zenón de Citio, que funda la escuela estoica hacia el 300 a.C., fue honrado oficialmente, por la ciudad, y alabado por "la educación que imparte a la juventud, por el tipo de vida que lleva, por la armonía entre su vida y sus discursos. Las comedias de la época hacen referencia a su vida austera: 'Un pan, higos, un poco de agua. Éste 'filosofa' una nueva filosofía: enseña el hambre y encuentra discípulos": FA 115.

Los escépticos no tienen un conjunto de verdades, dignas de fe, pero sí una forma de vida. "Los cínicos, por su parte, no argumentan ni imparten enseñanza alguna. Es su propia vida la que tiene, por sí misma, su sentido e implica toda una doctrina": FA 116.

Finalmente, todas las escuelas buscaban paz. Para eso el hombre debe cambiar su forma de pensar y su modo de ser: "En esta perspectiva, la filosofía parece ser una terapéutica de las preocupaciones, de las angustias y de la desgracia humana, desgracia provocada por las convenciones y las obligaciones sociales, según los cínicos; por la búsqueda de falsos placeres, de acuerdo con los epicúreos; por la persecución del placer y el interés egoísta, según los estoicos, y por las falsas opiniones, de acuerdo con los escépticos". (...) "todas esta filosofías pretenden ser terapéuticas", según A.-J. Voelke: FA 117. Así, se aprende "a gobernarse a sí mismo" y a gobernar bien a otros. 
Con todo, debemos distinguir: "por una parte, al epicureismo, para el cual la búsqueda del placer es lo que motiva toda la actividad humana, y por la otra, el platonismo, el aristotelismo y el estoicismo, para los cuales, conforme a la tradición socrática, el amor al Bien es el instinto primordial del ser humano": FA 117.

Además: "La filosofía cínica es únicamente una elección de vida, la elección de la libertad, o de la total independencia (autarkeia) con respecto las necesidades inútiles, el rechazo del lujo y de la vanidad (tuphos)" (...) "Su filosofía es pues totalmente ejercicio (askesis) y esfuerzo. Pues los artificios, las convenciones y las comodidades de la civilización, el lujo y la vanidad debilitan el cuerpo y el espíritu": FA 124-5. Pirrón buscaba despojarse del hombre, demasiado humano, y se ejercitaba en ser virtuoso y a su discípulo Filón de Atenas se le ve: "Viviendo lejos de los hombres en soledad, hablándose a sí mismo, sin preocupación por la gloria y las disputas": FA 128.

\section{1.- La filosofía en Epicuro}

En Epicuro la filosofía consiste: “en aspirar al único placer verdadero, el simple placer de existir. Pues toda la desdicha, toda la pena de los hombres procede del hecho de que ignoran el verdadero placer": FA 130. Así: "La misión de la filosofía, la misión de Epicuro, será pues ante todo terapéutica: habrá que sanar la enfermedad del alma y enseñar al hombre a vivir el placer": FA 130.

En palabras de Epicuro: "Pues así como no hay ningún beneficio en la medicina si no elimina las enfermedades del cuerpo, tampoco lo hay en la filosofía si no expulsa las dolencias del alma": Fragmentos 54. Así, uno puede gozar de uno mismo y asemejarse a Dios, según Rousseau. Por eso, para Montaigne: "De nuestras enfermedades, la más salvaje es despreciar nuestro ser": Ensayos III,13"13.

Y la clave de todo es la ascesis de los deseos para quedarse sólo con los "naturales y necesarios", que son fáciles de obtener (FA 132), y alejan el temor a la muerte: FA 136. Así, ni los dioses ni la muerte son de temer, el bien es fácil de adquirir y el mal fácil de soportar: FA 138. Para eso, los epicúreos llevan una vida sencilla en la comida y la ropa, renuncian a riquezas y honores, y viven retirados, en una atmósfera de amistad, con una cierta dirección espiritual, examen de conciencia y corrección fraterna que libera

13 Botton, Alain de, Las consolaciones de la filosofía. Taurus, Madrid 2004,5ª 170. 
la culpabilidad, y propicia la confianza y la libertad de la palabra, y "un diálogo corrector y formador": FA 139-140.

Así, Epicuro apareció a sus discípulos como: "un dios entre los hombres": Carta a Meneceo 135. Y él mismo había establecido el principio: "Haz todo como si Epicuro te mirara": Séneca CL 25,5. El ejercicio de la sabiduría es un gran placer. Y: "El placer supremo era contemplar la infinidad del universo y la majestad de los dioses": FA 140. Cicerón dice que Epicuro tenía una casa pequeña, con un tropel de amigos, esclavos y mujeres, unidos por el amor, con una gran conciencia "de la maravilla única" que es la vida, un gran placer, pero decía: "para vivir felices, no hay nada superior, más fecundo, más agradable, que la amistad": De finibus bonorum et malorum 1,20,65: FA 140-1.

\section{2.- El Estoicismo}

Para esta escuela "el bien moral" es "accesible a todos aquí abajo": FA 143. Pero: "la dicha no consiste en el placer o en el interés individual, sino en la exigencia del bien, dictada por la razón y que trasciende al individuo" (...) "La voluntad de hacer el bien es la ciudadela interior inexpugnable, que cada quien puede edificar en sí mismo. Es ahí en donde encontrará la libertad, la independencia, la invulnerabilidad, y, valor eminente-mente estoico, la coherencia consigo mismo": FA 143. Y, así, hay que desear siempre lo mismo, dice Séneca, lo "moralmente recto". Según Zenón, la vida estoica consiste en: "Vivir de manera coherente, es decir, conforme a una regla de vida única y armoniosa, pues los que viven en la incoherencia son desdichados": FA 144. El estoico cultiva la Física que distingue los bienes de los males y nos enseña la coherencia del ser vivo donde todo está relacionado con todo, la ética que se fundamenta en la Naturaleza, y la lógica que nos muestra la vida racional, pues: “¿Sería posible que hubiera orden en nosotros y que el desorden reinase en el Todo?": MA, Pensamientos IV, 27: FA 145.

Para los estoicos, todo lo dirige la Razón, y así: "todo está en todo, los cuerpos son todos orgánicos, el Mundo es un todo orgánico y todo sucede por necesidad racional": FA 145-6.Y, todo está en permanente metamorfosis: FA 153. Pero: "La Razón universal no puede actuar de manera diferente de como lo hace, precisamente porque es de una racionalidad perfecta": FA 146. La moral es posible por la elección libre del hombre, pues según Cleantes repetido por Séneca: "Los destinos guían a quien los acepta, arrastran a quien se les resiste": CL 107,11: FA 147.

Y, así: "La actitud moral recta consistirá en no reconocer como bueno o malo más que lo que es moralmente bueno o malo y en considerar ni bueno 
ni malo, luego indiferente, lo que no es moralmente ni bueno ni malo": FA 149. Entonces, será bueno o malo lo que dependa de nosotros, lo que no sea indiferente y sin valor moral pues no está en nuestras manos. Por eso, nos aconsejan: "No procures que lo que sucede suceda como lo quieres, sino quiere que lo que sucede suceda como sucede, y serás feliz": Epicteto, Manual, 8: FA 149. Todo acontecimiento hay que situarlo en la Naturaleza y la Razón Universal, y así elegir nuestras posiciones y acciones según esa voluntad natural. Lo importante es la intención de actuar bien. Así, el estoico siempre se procura conformar con el destino, pero participa en la vida política y social: "Deseo hacer esto, si el destino lo permite": FA 151.

Según Séneca, De Clementia, II,3,3: "Ninguna escuela tiene más bondad y dulzura, ninguna tiene más amor a los hombres, más atención al bien común. El fin que nos asigna es ser útiles, ayudar a los demás y preocuparnos no sólo de nosotros mismos, sino por todos en general y por cada uno en particular": FA 151. Su mejor ejercicio espiritual es el "dominio del discurso interior" (FA 152), atenerse a la realidad, tal cual es, como enseña la física que nos sumerge en el todo y "conduce al filósofo a consentir con amor a los acontecimientos deseados por la Razón inmanente al cosmos": FA 153. Un último ejercicio es el de la muerte, y la previsión de los males (praemeditatio) y obstáculos, pues el mal esperado es un mal aminorado por acostumbrado.

También hay que tomar conciencia del valor infinito de cada instante: "Hay que llevar a cabo cada acción de la vida como si fuera la última": MA II,5,2. El estoicismo conjunta física, lógica y ética, aunque Aristón de Quío quiso reducir todo a la ética: FA 154. El estoico está siempre atento a lo que hace (ética) pero también a lo que piensa (lógica) y a su lugar en el cosmos (física), pues: "el hombre atento vive siempre en presencia de la Razón universal inmanente al cosmos, viendo todas las cosas en la perspectiva de esta Razón y aceptando alegremente la voluntad de esta última": FA 155. Esta es una misma Razón en la naturaleza (física) en la comunidad humana (ética) y en el pensamiento individual (lógica), y el filósofo procura seguir su camino.

\section{3.- La Academia Nueva}

La sabiduría es una búsqueda que jamás termina: Apología, 23 b, 38 a, 41 b-c. Por eso, hay que cuestionarse todo y librarse de prejuicios frente al falso saber: FA 157. "En el hombre existe el deseo fundamental y original del bien y una tendencia natural a actuar de buena manera": FA 158. Luego, 
la Academia evoluciona hacia el probabilismo. Según Cicerón: "Nosotros, académicos, vivimos al día (es decir, juzgamos en función de los casos particulares) (...) y por ello somos libres": Tusculanae Disputationes V,11,33. Así: "La filosofía es ante todo un arte de vivir": Plutarco, Propósitos de mesa I,2,613 b.

Para Voelke: "el discurso filosófico escéptico conduce a su propia autosupresión, para no dejar lugar más que a un modo de vida, que además pretende no ser filosófico": FA160. Y su "elección de vida" es la paz y la tranquilidad del alma, no pronunciarse sobre nada y suspender el juicio "por amor a los hombres".

Según Sexto Empírico, y sobre todo Enesidemo, la diversidad de costumbres, de percepciones, de reacciones, de disposiciones, de ilusiones de los sentidos, etc., impide pronunciarse. Agripa decía que todo es muy contradictorio. Y: "por último, todo es relativo, todas las cosas se suponen mutuamente, y es imposible conocerlas tanto en su conjunto como en el detalle": FA 161. Así, según Voelke, hay una epojé filosófica, y una filosofía como patología y una filosofía como cura, como en Wittgenstein. Entonces, de la filosofía sólo queda ya: "Un modo de vida que además será un modo de vida no filosófico": FA 162.

\section{4.- Algunas características generales de la vida filosófica ${ }^{14}$}

La enseñanza pública de la filosofía culmina cuando Marco Aurelio funda, en 176 d.C., cuatro cátedras imperiales pagadas por el tesoro del Imperio que enseñarán: platonismo, aristotelismo, epicureismo y estoicismo: FA 164. A veces, la enseñanza consiste en la exégesis de textos de autoridades como el Banquete, Fedro, o de Aristóteles, Epicuro, etc: FA 167. Pero, a la vez: "la filosofía sigue siendo concebida como un esfuerzo de progreso espiritual, un medio de transformación interior" (FA 166): "Se intenta volverse mejores y más mesurados": FA 167. Pero, antes: "se aprendía a vivir aprendiendo a hablar", ahora se aprende la filosofía en sus textos: FA 168. Esa es la escolástica que se impone en el mundo medieval, según M.-D. Chenu. Y, es la época de los profesores que suplantan a los maestros: FA

14 Según Hadot, le influyen mucho: RaBBow, P., Seelenführung. Methodik der Exerzitien in der Antike, Munich 1954. La obra de su mujer HADOT, Ilsetraut, Seneca und die griechischrömische Tradition der Seelenleitung, Berlín 1969. VOELKE, A.-J, La philosopie comme therapie de l'âme, prefacio de P. Hadot, Freiburg-Paris 1993. Y: DOMANSKI, J., La philosophie, théorie ou mode de vie. Les controverses du Moyen Âge et du début de la Reinaissance, prefacio de P. Hadot, Freiburg-Paris 1996: FA 16-17. 
168. Pero Epicteto dice que cuando se le pide que comente a Crisipo: "me ruborizo, si no puedo mostrar una conducta similar a sus enseñanzas y que concuerde con ellas" (Coloquios III,21-23, Manual \& 49): FA 170.

Según Plutarco, Platón y Aristóteles culminan una "epóptica" o revelación suprema. A partir el s. II ${ }^{\circ}$ d.C.: "la filosofía fue concebida como un itinerario espiritual ascendente, que corresponde a una jerarquía de las partes de la filosofía": FA 171. Así, la ética purifica el alma, la física revela que el mundo tiene una causa trascendente y la metafísica o teología o "epóptica" "aporta la contemplación de Dios". Eso hace Platón en algunas de sus obras como Alcibíades, Fedón, Timeo, Parménides y Filebo. Hay unas obras para principiantes y otras para los que van progresando: FA 172.

Pero, tanto en Epicteto como en Plotino: "las respuestas del maestro estaban destinadas a provocar que el alumno cambiara de vida o progresara espiritualmente": FA 173. Así: "La comunidad de vida es uno de los elementos más importantes de la formación" (...), y el profesor "desempeña el papel de un verdadero director de conciencia, interesado en los problemas espirituales de sus alumnos": FA 173. Y, como en los pitagóricos, se impone una forma de vida con diversos hábitos de comidas, vestidos, tabúes y consejos morales o prescripciones rituales, elección de candidatos, noviciado en silencio, comunidad de bienes, ascesis y vida contemplativa. Así, el platonismo prolonga el pitagorismo: FA 174.

Porfirio piensa que el modo de vida filosófico se distingue del de los otros hombres, y no se dirige a las gentes de oficios manuales ni a los políticos sino al que ya pensó en preguntas como: “¿Quién soy?' ¿De dónde vine?' ‘¿A dónde hay que ir?', y que se fijó, en su alimentación, y en demás campos, principios diferentes de los que rigen a los demás estilos de vida" (Porfirio, De abstinentia 1,27,1): FA 175. Porfirio desea "vivir conforme al espíritu", y esa vida contemplativa, como en Aristóteles, nos lleva a la felicidad, porque es en nosotros "vida" y "naturaleza". "La contemplación no es, pues, conocimiento abstracto, sino transformación de uno mismo" (Porfirio, De abstinentia, 1,29,6): FA 175.

Esta transformación, que es vuelta al yo y a lo divino, según Aristóteles, es incluso buena para la salud: FA 176. Pues produce una gran atención a sí mismo y a los demás, y es un camino de unión con Dios, que es la verdad y felicidad verdadera, y su amor definitivo, como lo demuestra la vida de Plotino: FA 178-9. Hay una aristotelismo místico como el de Alejandro de Afrodisia que es "la opción por un modo de vida", y: "la experiencia inefable que invade al individuo y trastorna toda la conciencia del yo, por un sentimiento de presencia inexpresable": FA 180.Y, es una experiencia unitiva, "no discursiva", de una Presencia que está en el propio fondo, donde el 
"Espíritu-Intelecto queda prendado de amor", "ebrio de néctar", "alcanza su plenitud en el gozo" (Enéadas VI,7 (38), 35,19-33: FA 185. Según Plotino, para no quedarse en puras palabras: "Solo la experiencia moral o mística puede dar un contenido al discurso filosófico": FA 186.

Epicteto ataca a los que "disertan sobre el arte de vivir como hombres, en lugar de vivir ellos mismos como hombres, que hacen, conforme a la expresión de Séneca, del amor a la sabiduría (philosophia) un amor a la palabra (philologia) (Séneca CL 128,23): FA 192.

Por tanto, según Plutarco, el discurso filosófico es un medio privilegiado para hacerse mejores, y de "actuar sobre sí mismo y sobre los demás"(...) "En esta perspectiva, se le puede definir como un ejercicio espiritual, es decir, como una práctica destinada a llevar a cabo un cambio radical del ser": FA 194. Y esto vale para todos: cada uno debe meditar su vida, llevar una vida de sabio, y someterse al Bien y a la Razón. En este sentido: "Las preguntas socráticas lo obligan pues a preocuparse por sí mismo y por consiguiente a cambiar de vida": FA 195.

Así se forma una comunidad de vida y de personas preocupadas por sí mismas y por los otros. Y, ya sea en Pirrón o en Cleantes o en Horacio, empapado de pensamientos sabios y del bien: "El diálogo consigo mismo es una costumbre generalizada en toda la Antigüedad": FA 197. Epicteto mismo recomienda: "Ve a pasearte solo, conversa contigo mismo": Coloquios III,14,1. "A lo largo de nuestra indagación, encontramos en todas las escuelas, hasta entre los escépticos, 'ejercicios' (askesis meleté), es decir: prácticas voluntarias y personales destinadas a producir una transformación del yo. Son inherentes al modo de vida filosófico": FA 197.

Y como rasgos más comunes hallamos: La conformidad consigo mismo y la concentración del yo en el yo y su independencia, en "dejar atrás el yo egoísta" y buscar "el yo puro". Dice Plotino: "retira todo lo superfluo, endereza lo oblicuo, purificando todo lo tenebroso para volverlo brillante, y no dejes de esculpir tu propia estatua hasta que brille en ti la claridad divina de la virtud" (Enéadas I,6(1),9,7 y ss.): FA 210. Eso mismo dice M. Aurelio exhortando a vivir "el presente", pues "el resto o ya se vivió o bien es incierto": MA, Pensamientos III,10,1. Y, no son más que penas o placeres imaginarios.

Así, se rechazan las vanas esperanzas y los pesares ya pasados. Pues: "La conciencia de sí no es más que la conciencia de un yo que actúa y vive en el momento presente" (...) "Este ejercicio de la conciencia de sí se reduce, pues, a un ejercicio de atención a sí mismo (prosoché) y de vigilancia" (FA 211) que mantiene "la pureza de intención", la sintonía "con la Naturaleza universal" y "los principios y las reglas de vida que la expresan": FA 212. 
Como sentencia Horacio: "Que el alma dichosa en el presente, se niegue a inquietarse por lo que vendrá después". "El presente, piensa en utilizarlo bien, con mente serena. Todo lo demás es arrastrado como un río" (Carmina II,16,35; III,29, 33): FA 214. O, como aconseja Séneca: "En el momento de irnos a acostar, digamos con gozo y alegría: 'Viví, recorrí el curso de la vida que me había asignado la fortuna'. Si un dios nos da un mañana por añadidura, recibámoslo con alegría": CL 12,9;101,10: FA 213. Ese sentir que se vive es un gran gozo para Aristóteles y Epicuro, a fin de no volverse al pasado ni precipitarse en el futuro en busca de "el dinero o el poder o la gloria": FA 213-4. Como dice Cicerón: "La vida del insensato es ingrata e inquieta. Toda ella se precipita hacia el futuro": De finibus bonorum et malorum, I,18,60: FA 214.

Para Epicuro: "Un solo instante de gozo es tan perfecto como una eternidad de gozo": FA 216. Y, por lo demás, hay que aumentar el amor a la vida y suprimir el temor a la muerte: "Es una sola y misma cosa el ejercicio de vivir bien y el ejercicio de morir bien" (Carta a Meneceo \&126): FA 216. Y, por otra parte: "el ser no es el no ser, no hay transición del ser a la nada"(...) "Se puede decir entonces que en cierto sentido uno de los ejercicios filosóficos más fundamentales es el de la muerte": FA 217. Pero la concentración en sí mismo y el examen de conciencia también son importantes. Este ejercicio "de la espiritualidad cristiana" está muy difundido "en las escuelas filosóficas de la Antigüedad": FA 217. Se trata de tomar conciencia de la dispersión y la alienación humana o como dice Epicuro: "El conocimiento de la falta es el inicio de la salvación"(CL 28,9, que cita un texto epicúreo): FA 218. También, para los estoicos: "El punto de partida de la filosofía (...) es la conciencia de la propia debilidad" (Epicteto, Coloquios II,11,1): FA 218. Zenón de Citio y Platón aconsejan examinar los sueños, y, lo mismo hace el escritor cristiano Evagrio Póntico'15: FA 218. El neopitagorismo, Porfirio y Epicteto, aconsejan examinar nuestros actos para corregir el mal y alegrarse del bien.

Galeno aconseja el examen, ante un hombre de edad, es decir cierta dirección espiritual, y "luego examinarse uno mismo por la mañana y por la noche": FA 219. Séneca, siguiendo a Sexto, aconseja escudriñar todo un día siendo acusador, juez y abogado propio: CL 28,10. Epicteto pide apuntar los incumplimientos. M. Aurelio y Epicteto aconsejan examinarse por la mañana para preparar el día y no afligirse inútilmente: "De mañana, en cuanto tè

15 Sobre Evagrio Póntico y la terapia de la amargura de la vida Cf.: RivAs REBAQue, Fernando, Terapia de las enfermedades espirituales en los Padres de la Iglesia. San Pablo, Madrid 2008, 126-130. 
levantes, pregúntate: ‘¿Qué me queda por hacer para adquirir la impasibilidad y la ausencia de perturbación? ¿Quién soy? ¿Un cuerpo? ¿Una fortuna? ¿Una reputación? Nada de todo eso. ¿Pero qué? ¿Soy un ser razonable?"' (Coloquios IV, 6, 34): FA 221.

Hay un movimiento de concentración en sí y de dilatación del yo en el Todo y en el mundo, en lo divino y el universo humano infinito, que está también en Epicuro: FA 222. Para Séneca la elevación del alma es el sentido fundamental de la Física, y su provecho principal: "sabré que todo es pequeño cuando haya tomado la medida de Dios" (Quaestiones natureles, I, prólogo 17): FA 228. Así, se goza del presente, sin depender de lo que aún no es, se "carece de esperanza y de deseo", y uno "está satisfecho con lo que posee", pues como Dios lo posee todo: FA 231.

Para Simplicio, el filósofo es: "un escultor de hombres", de "ciudadanos leales", padre y pedagogo común purifica y se purifica, "consejero y protector" a fin de "cooperar en el cumplimiento de todo bien, regocijándose con quienes tienen dicha, compasivo con quienes están afligidos y consolándolos": FA 232. Esa educación, que antes hacía la ciudad, la hacen ahora las escuelas filosóficas, unas a nivel más individual otras de modo más social, como ha mostrado I. Hadot: FA 232.

Por lo demás, la dirección espiritual tenía como fin hacer elecciones razonables, en el decurso de la vida, y así se procura: "Haber tenido la idea de la necesidad que yo tenía de corregir mi estado moral y de cuidar de él" (MA, Pensamientos I,7,1): FA 233. P. Rabbow e I. Hadot han analizado este tema de la dirección espiritual en las escuelas filosóficas. Esta práctica, provoca, como Sócrates, un choque en el alma de la persona, pero también atiende a su carácter, como hace Platón, que dice necesitar un freno para Aristóteles, y un acicate para Jenócrates o que éste haga un sacrificio a las Gracias: FA 233.

El maestro debe ser sincero, "escuchar con simpatía" y "hablar libremente". Así: "la tradición epicúrea reconoce el valor terapéutico de la palabra": FA 235. Metrodoro corrige a Pitoles en temas del amor, Séneca aconseja a Lucilo, Musonio Rufo lo hace en sus escritos y Epicteto en sus Coloquios. Marco Aurelio fue aconsejado por J. Rústico, Porfirio por Plotino, y Edesio de Pérgamo corregía la arrogancia con la armonía y la responsabilidad: FA 236. Pero no siempre la tarea es fácil y algunos: "lo soportan mal y lo encuentra indiscreto": FA 237.

Así: "Las filosofías antiguas desarrollaron pues todo tipo de prácticas de terapia del alma, ejercitándose por medio de diferentes formas de discurso, trátese de la exhortación, de la reprimenda, del consuelo o la instrucción": FA 237. "En Grecia se sabía desde Homero y Hesíodo que era posible modificar las decisiones y las disposiciones interiores de los hombres eli- 
giendo con habilidad las palabras capaces de persuadir": FA 237. Esa dirección espiritual y "la terapia de las almas" conducirá a las filosofías antiguas a un gran conocimiento del "corazón humano": FA 238. Así, los tratados de retórica describen las disposiciones fundamentales de los oyentes.

Según Lucrecio: "Cada uno intenta huir de sí mismo (...) pero permanece apegado a su pesar a ese yo al que detesta" (De rerum natura III, 1068): FA 238. Para Séneca, ese es un tedio que llega "hasta el asco" y hace decir: "hasta cuándo las mismas cosas" (CL 24,36): FA 238. Sereno confiesa a Séneca: "La disposición en la que me sorprendo muy a menudo (pues ¿por qué no me confesaría a ti como a un médico?) es no estar francamente liberado de mis temores y de mis repugnancias de antaño, ni por completo bajo su dominio"(De tranquillitate animi, I,1): FA 239.

M. Aurelio invita a ayudar al otro: "sin hacerle sentir que se le soporta, pero con franqueza y bondad" (...) "con dulzura, sin ironía, sin humillar, sino con afecto, con un corazón exento de amargura, no como se haría en una escuela, ni para hacerse admirar por alguien si asistiera a la conversación, sino en verdad cara a cara, aun si otros están presentes": Pensamientos $\mathrm{XI}, 13,2$, y XI,18,18. Hay que hacer el bien con sencillez, impulsados por "el respeto y el amor a los demás", sin que se note la dulzura, pues: "Hay que ser de los que hacen el bien inconscientemente" (Pensamientos V,6,3): FA 240.

Y finalmente: "Si, pues, la filosofía no sólo es un discurso, sino una elección de vida, una opción existencial y un ejercicio vivido, es porque es deseo de la sabiduría": FA 240. El sabio es autónomo, feliz con su vida contemplativa, y encuentra en ella: "la felicidad y la perfecta independencia": FA 242. Sólo debe preocuparnos lo que depende de nosotros que es para los estoicos: "el bien moral, es decir, la intención de hacer el bien porque es el bien": FA 242. Y, así, al hombre "justo y firme" nada le altera su libertad interior en comunión con el mundo y la divinidad: Horacio, Carmina III, 3,1-8. De este modo, la figura del sabio "tiende a volverse semejante a la de Dios", también en su serenidad y alegría ante el mundo: FA 246. Entonces, el sabio deja de temer a los dioses porque "llama a los sabios amigos de los dioses y a los dioses amigos de los sabios": FA 247. Para Aristóteles, en la vida del espíritu: "de nuevo lo divino es el modelo del sabio" (FA 247). Pero, según Nietzsche, los sabios atribuyeron a Dios su propio oficio: FA 249.

En todo caso, la república de los sabios no tiene leyes ni templo ni prohibiciones, pues: "la razón del sabio basta para prescribirle lo que debe hacer": FA 250. El sabio tiene a todo el mundo siempre presente, pues él mismo es parte del mundo y forma con él un todo: FA 250. Séneca dice que pasa mucho tiempo contemplado la sabiduría y mirando al mundo, con una mirada siempre nueva: "este mundo que me sucede muchas veces contem- 
plar como si lo viera por primera vez" (CL64,6): FA 250. El mismo Séneca dice sobre Sexto que: "Al revelarte las grandezas de la vida feliz no te quitará la esperanza de alcanzarla": FA 251.

Para Séneca, el hombre sin miedo sin pasiones y feliz en la adversidad es como un dios. Y, así: "En cada hombre de bien habita un dios. ¿Cuál es? Ninguna certeza, pero es un dios" (CL41,4): FA 251. Entonces, el hombre quedaría liberado del peso de los hechos y las cosas, de la insatisfacción y la angustia de la vida mientras que ahora estamos: "Así tensos y atareados por la persecución de nuestros intereses mundanos, no tenemos ni la menor idea del inmenso alivio que representaría el depósito de la carga, es decir, el renunciamiento (la renuncia) a afirmarnos a toda costa en contra del orden del mundo y en detrimento del otro": FA 254.

\section{5.- El cristianismo como filosofía revelada}

Según Hadot, desde muy pronto el cristianismo se presentó como una filosofía revelada, y puso el Logos cristiano como el origen de todas las cosas, muy en la línea de Heráclito. En especial, los apologistas cristianos "utilizaron la noción de Logos para definir el cristianismo como la filosofía": FA 25816. Y, así: "Si filosofar es vivir conforme a la Razón, los cristianos son filósofos, pues viven conforme al Logos divino (Justino, Apologies, I,46,3-4)": FA 259.

Es más, según Clemente de Alejandría, "el cristianismo, que es la revelación completa del Logos, es la verdadera filosofía, la que 'nos enseña a conducirnos de manera que nos asemejemos a Dios y a aceptar el plan divino como principio directivo de toda nuestra educación": FA 259. Así, el cristianismo se moverá desde el: “¿Qué tiene que ver Atenas con Jerusalén?” de Tertuliano, al "nova non philosophandi philosophia", de Lactancio (PL 7,10 A), para terminar "als der wahren Philosophie akzeptieren"17.Y, entonces, la filosofía cristiana se presentará como la griega: "al mismo tiempo como discurso y modo de vida": FA 259.

\footnotetext{
16 Según el profesor L. Ferrero, Heráclito había hablado, en varios sentidos, del Logos. "Pero fue el primer estoicismo el que introdujo en Grecia la concepción semítica de la palabra, dándole un nuevo sesgo a la filosofía. No es fácil entender el logos estoico como palabra cósmica y palabra seminal si no tenemos en cuenta la tradición semítica del dabar en Zenón de Citio, el fundador del estoicismo, un cretense de origen fenicio que conoce el arameo": Ferrero Carracedo, Luis, Razón Dramática y Pensamiento. Fundación Universitaria Española, Madrid 2008, 278-9.

17 HeInZmanN, Richard, Philosophie des Mittelalters, Kohlhammer, Stuttgart 2008, $3^{\mathrm{a}}$, 26,38.
} 
Y, como el discurso filosófico antiguo era exégesis de textos claves, el discurso cristiano lo será de la Biblia. Pero, sobre todo, el cristianismo se presenta como una filosofía "porque es un estilo de vida y un modo de ser" como "la filosofía antigua era ella misma un estilo de vida y un modo de ser": FA 260. Así, Clemente de Alejandría recomienda ejercicios de prudencia y de tranquilidad del alma así como "la atención (prosochê) a sí mismo": FA 261.

Del mismo modo, algunos grandes Padres de la Iglesia Oriental, del s. IV, y Doroteo de Gaza, en el VI, "no dejaron de interpretar en el sentido de la 'filosofía cristiana' el fenómeno del monaquismo": FA 262. S. Atanasio, en la Vida de Antonio dice que éste "se puso a prestar atención a sí mismo", y en su muerte dijo a sus discípulos: "Vivid como si debierais morir cada día, prestando atención a vosotros mismos y recordando mis exhortaciones": FA 263.

Gregorio Nacianceno hablará de "concentración en uno mismo": FA 263. En S. Basilio encontramos todos los temas del estoicismo y el platonismo: atención a nosotros mismos y a nuestra razón, gran don divino, "velar por nosotros mismos, es decir por nuestra alma", cuidar de su belleza, y no tanto de nuestras posesiones y nuestro cuerpo, "examinando nuestra conciencia y conociéndonos a nosotros mismos": FA 264.

La atención a sí mismo implica el examen de conciencia. Antonio aconseja hacerlo por escrito: "Que cada quien anote por escrito las acciones y los movimientos de su alma, como si tuviese que darlos a conocer a los demás'. Preciosa notación psicológica: el valor terapéutico del examen de conciencia será mayor si éste se exterioriza por medio de la escritura": FA 264. Doroteo de Gaza aconseja examinarse cada 6 horas, y hacer un balance "cada semana, cada mes, cada año". De este modo práctico, los Apotegmas de los Padres se parecen a las Sentencias de los filósofos célebres, recogidas por D. Laercio y a los Hechos y Dichos Memorables de Valerio Máximo.

Todo esto se medita para "sacar provecho de todos los acontecimientos", con unos principios adecuados, y con "la atención a sí mismo" se busca liberarse totalmente de las pasiones y el cuerpo, por el desprendimiento y la apaitheia, con pequeñas renuncias para superar, poco a poco, "la voluntad egoísta". Así, como dice Doroteo de Gaza: "suceda lo que suceda, eso lo contenta, como si viniera de él" (...) "y resulta que siempre hace su voluntad, pues no desea que las cosas sean como las quiere, sino que desea que sean tal cuales son": FA 265. Aquí vemos el eco "de la célebre octava sentencia del Manual de Epicteto: 'No pretendas que lo que sucede suceda como lo quieres, sino desea que lo que sucede suceda como sucede, y serás feliz'. Al igual que el estoico, el monje desea así cada momento presente tal cual es": FA 266. 
Del mismo modo, Evagrio Póntico contempla con la razón, combate por la virtud y se atiene a la naturaleza en sus deseos, y afirma, siguiendo el neoplatonismo de Gregorio Nacianceno, que: "Separar el cuerpo del alma no corresponde más que a Aquel que los unió; pero separar el alma del cuerpo atañe precisamente a quien tiende a la virtud. Pues nuestros Padres llaman a la anacoresis (la vida monástica) ejercicio de la muerte y fuga del cuerpo": FA 267. Para Evagrio, la muerte en la que se adiestra ese filósofo, que es el monje, es la de las pasiones.

De este modo: "la vida filosófica profana y la vida monástica tenían en el fondo muchas analogías": FA 268. Los filósofos antiguos no se fueron al desierto, como los monjes, pero sí entraban en una comunidad, bajo la dirección de un maestro, con ciertas comidas comunes, examen de conciencia y confesión de faltas si son epicúreos, renunciaban a las riquezas, se consagran a la contemplación para conseguir la unión mística si son platónicos o pitagóricos, o llevan una vida muy especial como los cínicos. A su vez: "El cristianismo es indiscutiblemente un modo de vida. No plantea pues ningún problema el que haya sido presentado en calidad de filosofía. Pero, al hacerlo, adoptó ciertos valores y ciertas prácticas propios de la filosofía antigua": FA 268.

Así, se toman algunos ejercicios espirituales, originarios de la filosofía pagana, como la renuncia a la propia voluntad, ejercicio de la muerte, un cierto ascetismo, examen de conciencia, etc., que se integraron en una práctica cristiana más amplia, que supone siempre la gracia de Dios, la humildad y la imitación de Cristo, y que confiere a todo el proceso un nuevo significado por medio de textos bíblicos, como: "Muero cada día" de 1Cor 15,31 y otros. Así, Evagrio Póntico escribe: "El cristianismo es la doctrina de Cristo, nuestro Salvador; está compuesta de la práctica, la física y la teología" (Traité practique1)": FA 270. Esas son las tres partes de la filosofía clásica que corresponden también a los pasos fundamentales del progreso cristiano: purificación que nos aleja de las pasiones (praxis), la contemplación del mundo y la naturaleza como creados por Dios (física), y el camino a la unión con Dios (teología): FA 271.

Del mismo modo, según Hadot: "En los años consecutivos a su conversión, Agustín de Hipona cotejó, en su libro Sobre la verdadera religión, el platonismo y el cristianismo. A sus ojos, lo esencial de las doctrinas platónicas y lo esencial de las cristianas se empalman": FA 271. La lógica nos lleva de la razón a la divinidad, la física del mundo a su Creador, y la ética nos aparta de lo terreno para "gozar de la contemplación de Dios y de encontrar en ella la vida eterna": FA 272. La diferencia fundamental sería que Platón no pudo convertir a las masas populares ni sacarlas de las cosas 
del mundo para "recogerse en sí mismas y mirar hacia la patria", que es Dios, pero el cristianismo sí lo consiguió. De ahí, que para Hadot, en Agustín el platonismo y el cristianismo son, en esencia, lo mismo, por eso había dicho Nietzche: "El cristianismo es un platonismo para el pueblo": FA 272.

Del mismo modo, para Hadot, el Evangelio del reino de Dios fue sustituido por "el ideal filosófico de una unión con Dios, de una deificación, logrado por medio de la ascesis y de la contemplación": FA 272. Y, así, a veces, la vida cristiana es menos la vida del hombre que la del alma: FA 272. Pero, en todo caso, según Hadot: "la atención a uno, la búsqueda de la impasibilidad, de la paz de alma, de la ausencia de preocupaciones, y sobre todo la huida del cuerpo, se volvieron los objetivos primordiales de la vida espiritual": FA 273. "De esta espiritualidad, fuertemente marcada por el modo de vida de las escuelas filosóficas antiguas, heredó el modo de vida cristiano de la Edad Media y de los tiempos modernos": FA 273.

Sobre estas afirmaciones de Hadot, acerca de la huida del cuerpo y la salvación del alma, anotar solamente de paso, pues ahora no es el momento de entrar en este arduo tema, que esta interpretación no casa bien con la escandalosa frase, del más clásico de los teólogos cristianos, Sto. Tomás de Aquino, al comentar 1Cor15, aireada por Hanna Arendt: "Si sólo mi alma se salva yo no me salvo"...Y la no menos escandalosa afirmación, de S. Agustín, en La ciudad de Dios, que el alma no sería del todo feliz ni perfecta en el cielo sin el cuerpo. También Agustín se opone decididamente a la huida del cuerpo de Porfirio, pues está en juego el tema de la Encarnación cristiana, que está en la base del famoso dicho del máximo apologista cristiano Tertuliano: "caro cardo salutis"18. Otra cosa es que el cristianismo cultural, o mejor dicho inculto, se haya vivido, en gran parte como lo presenta Hadot, de ahí la queja de Nietzsche, y, también, la de un gran creyente como era Unamuno.

En todo caso, es cierto, que el cristianismo se representó, muy pronto, como: "un modo y una elección de vida que implica cierto discurso, la elección de la vida conforme a Cristo. En este modo de vida cristiano y además en el discurso cristiano, fueron absorbidos e integrados muchos elementos de la filosofía tradicional grecorromana": FA 274; 277. Pero aunque el platonismo y el aristotelismo tienden a convertirse en discursos teóricos, siempre queda un resto de la idea original, como pasa con el neoplatonismo que une a ambos, y también permanece, ese resto, en las universidades medie-

18 Cf. Torelló, Joan Baptista, Psicología y vida espiritual. Rialp, Madrid 2008, 31-2. 
vales donde había una "filosofía como modo de vida", según ha mostrado J. Domanski: FA 275. Así, el cristianismo refina el aristotelismo y éste provee nuevas ideas para formular los dogmas de la Trinidad y la Encarnación: FA 277.

Según Gilson, la fe cristiana une siempre "ciencia y vida". Y: "La gran superioridad del cristianismo consistía, precisamente, en que no era "un simple conocimiento abstracto de la verdad, sino un método eficaz de salvación"': FA 280. Estamos ante una gran oposición entre la universidad que da diplomas y forma funcionarios, por medio de otros funcionarios, pero no educa "para el oficio de hombre" como hace la filosofía antigua que: "se dirige a cada individuo para transformarlo en la totalidad de su personalidad": FA281. Como lo dice Wittgenstein: "A fin de cuentas, una filosofía no puede ser más que la expresión de una experiencia humana ejemplar": FA 282.

Así: "algunos filósofos, desde la Edad Media hasta nuestros días, se mantuvieron fieles a la dimensión existencial y vital de la filosofía antigua": FA 282. Boecio de Dacia, al comentar la Ética a Nicómaco: "considera que el fin del hombre y su felicidad consiste en vivir conforme a la parte más elevada de su ser, es decir, a la inteligencia destinada a contemplar la verdad. Una vida así está acorde con el orden de la naturaleza, que supeditó las capacidades inferiores a las superiores": FA 282. Cuando se llega al final de la filosofía, se saborea la sabiduría por sí misma. Y, en ese sentido abundan Dante y Eckhardt: FA 284. Petrarca pide una ética que ayude a ser mejor y no sólo a ser un profesor "sentado en una cátedra", pues para él: "Es más importante desear el bien que conocer la verdad": FA 284.

Para Erasmo, sólo es filósofo "aquel que vive de manera filosófica" como Sócrates, Diógenes, Epicteto, pero también el Bautista, Cristo y los Apóstoles o los Padres de la Iglesia (Erasmo, Adagia, 2201 (3,3,1)": FA 284. Para Montaigne: "Mi oficio y mi arte es vivir" (...) "Nuestra más grande y gloriosa obra maestra es vivir con propósito. Es una absoluta perfección, y como divina, saber gozar lealmente de su ser": FA 285. Foucault cree que es Descartes el que teoriza la filosofía, pero Hadot piensa que cuando éste escribe sus "Meditaciones, sabe muy bien que, en la tradición de la espiritualidad antigua y cristiana, la palabra significa un ejercicio del alma" (...) "un trabajo sobre sí mismo": FA 285. Es una obra que requiere tiempo para interiorizar la nueva conciencia conquistada y "volverme poco a poco más conocido y familiar mí mismo": FA 287. Además, sus Cartas a la princesa Isabel, son, hasta cierto punto, de dirección espiritual.

Para Kant, también la filosofía es esfuerzo hacia la sabiduría: "La filosofía, dice, es la doctrina y el ejercicio de la sabiduría (no simple ciencia)": FA 287. Y, afirma que, en los antiguos, la clave de su filosofía es: "el destino 
del hombre y los medios para alcanzarlo": FA 289. Así, lo que puedo saber, lo que debo hacer y lo que me es lícito esperar se resume en: “QQué es el hombre?": FA 292.

Muchos otros autores como Rousseau, Nietzche, Marx o Merleau-Ponty, "concibieron la filosofía como una actividad concreta y práctica y como una transformación del modo de vivir o de percibir el mundo": FA 293. En el existencialismo, vemos que la filosofía se plantea como un humanismo o alternativa de vida humana, $y$, también, a veces, como un sentido cristiano de vida como ocurre en Kierkegaard, G. Marcel o M. Mounier: FA 295. La filosofía, en Kant, interesa a la razón pero "por la elección de un modo de vida": FA 295.

Así, también, en Wittgenstein: "Lo que motiva el Tractatus es en realidad el afán de llevar al lector a cierto modo de vida, a cierta actitud, que además es totalmente análoga a las opciones existenciales de la filosofía antigua (Tractatus...6.4311). 'Vivir en el presente', sin lamentar ni temer ni esperar nada": FA 296. Así, todo discurso filosófico trata de formar y "transformar, es decir, de modificar la manera de vivir y de ver el mundo": FA 297. Esta concepción antigua sigue hoy muy vigente, pues "muchos filósofos de la época moderna, de Montaigne hasta nuestros días, no consideraron la filosofía como un simple discurso teórico, sino como una práctica, una ascesis y una transformación de sí”: FA 297. O como lo dice el Papa Benedicto XVI: "El filósofo era más bien el que sabía enseñar el arte esencial: el arte de ser hombre de manera recta, el arte de vivir y morir": Spe Salvi 6.

El verdadero filósofo sería "un hombre que lleva una vida filosófica", porque practica la filosofía, "así como el cristiano puede ejercer el cristianismo". Quien practica como el estoico o el epicúreo descubre el gozo del presente, el misterio y el esplendor de la vida, el origen del mundo y logra la serenidad: FA 299. Se trata de un esfuerzo por tomar conciencia de nosotros mismos y nuestro ser en el mundo, de nuestro ser con el otro y también de "volver a aprender a ver el mundo" (M. Ponty) para ponernos en el lugar del otro y superar nuestra parcialidad: FA 299.

De este modo, "el hombre contemporáneo, comprometido en la lucha política, reconoce que puede y debe vivir como filósofo". Como lo dijo G. Friedmann: ";'Alzar el vuelo', cada día! Por lo menos un momento que puede ser breve, a condición de que sea intenso. Cada día un 'ejercicio espiritual', solo o en compañía de un hombre que también desee mejorar.

Ejercicios espirituales. Salir de la duración. Esforzarte por desnudar tus propias pasiones, las vanidades, el deseo excesivo de ruido en torno a tu nombre (que, de vez en cuanto, te carcome como un mal crónico). Huir de la 
maledicencia. Desnudar la piedad y el odio. Amar a todos los hombres libres. Eternizarse superándose.

Este esfuerzo en uno mismo es necesario, esta ambición, justa. Numerosos son aquellos que se embeben por completo en la política militante, en la preparación de la Revolución social. Raros, muy raros, los que, para planear la Revolución, desean hacerse dignos de ella": FA 299.

Pues bien, desde siempre, las escuelas filosóficas son laboratorios experimentales de formas de vida que nosotros podemos adoptar y experimentar sin temor, con todas sus diferencias y coincidencias, para abrirnos a nuevos horizontes de vida, de vivir el presente y ver las cosas desde más arriba sin olvidar nunca la acción: FA 300-1. Por lo demás: "Es necesario que el modo de vida filosófico se justifique en un discurso filosófico racional y motivado": FA 303. Es preciso ser críticos con los distintos modos de vida y su discurso, y "pensar por uno mismo", para vivir en nuestro mundo.

Como lo dice G. Friedmann: "Un sabio moderno (si existiera) no se apartaría hoy día, como lo hicieron tantos estetas con asco, de la cloaca de los hombres": FA 304. Un filósofo vive su soledad en un mundo desgarrado entre dos inconsciencias: "la que provoca la idolatría del dinero y la que resulta de la miseria y el sufrimiento de miles de seres humanos. En semejantes condiciones, sin duda alguna jamás podrá alcanzar la serenidad absoluta del sabio": FA 304.

Entonces, toda la filosofía nos enseña a actuar razonablemente y esforzarnos por vivir con sabiduría aunque el resultado, de nuestra acción, nos parezca muy limitado. Así, como advierte M. Aurelio: “¡No esperes la República de Platón, mas conténtate si una nadería progresa, y piensa en el hecho de que lo que resulta de esa nadería no es precisamente una nadería!" (Pensamientos IX, 29,5): FA 305. 